\title{
The role of the chromatin remodeler Mi-2 $\beta$ in hematopoietic stem cell self-renewal and multilineage differentiation
}

\author{
Toshimi Yoshida, ${ }^{1,5}$ Idit Hazan, ${ }^{1,3}$ Jiangwen Zhang, ${ }^{2,3}$ Samuel Y. Ng, ${ }^{1,3}$ Taku Naito, ${ }^{1}$ \\ Hugo J. Snippert, ${ }^{1}$ Elizabeth J. Heller, ${ }^{1}$ Xiaoqing Qi, ${ }^{1}$ Lee N. Lawton, ${ }^{1}$ Christine J. Williams, ${ }^{1}$ \\ and Katia Georgopoulos ${ }^{1,4}$ \\ ${ }^{1}$ Cutaneous Biology Research Center, Massachusetts General Hospital, Harvard Medical School, Charlestown, \\ Massachusetts 02129, USA; ${ }^{2}$ FAS Center for Systems Biology, Harvard University, Cambridge, Massachusetts 02138, USA
}

The ability of somatic stem cells to self-renew and differentiate into downstream lineages is dependent on specialized chromatin environments that keep stem cell-specific genes active and key differentiation factors repressed but poised for activation. The epigenetic factors that provide this type of regulation remain ill-defined. Here we provide the first evidence that the SNF2-like ATPase Mi-2 $\beta$ of the Nucleosome Remodeling Deacetylase (NuRD) complex is required for maintenance of and multilineage differentiation in the early hematopoietic hierarchy. Shortly after conditional inactivation of $\mathrm{Mi}-2 \beta$, there is an increase in cycling and a decrease in quiescence in an HSC (hematopoietic stem cell)-enriched bone marrow population. These cycling mutant cells readily differentiate into the erythroid lineage but not into the myeloid and lymphoid lineages. Together, these effects result in an initial expansion of mutant HSC and erythroid progenitors that are later depleted as more differentiated proerythroblasts accumulate at hematopoietic sites exhibiting features of erythroid leukemia. Examination of gene expression in the mutant HSC reveals changes in the expression of genes associated with self-renewal and lineage priming and a pivotal role of Mi-2 $\beta$ in their regulation. Thus, Mi-2 $\beta$ provides the hematopoietic system with immune cell capabilities as well as with an extensive regenerative capacity.

[Keywords: Mi-2ß; chromatin; HSC; multipotency; self-renewal; lineage priming]

Supplemental material is available at http://www.genesdev.org.

Received December 13, 2007; revised version accepted March 4, 2008.

The defining properties of somatic stem cells, their ability to self-renew and to progress through available differentiation pathways, are critical for the life-long tissue integrity of multicellular organisms (Weissman 2000; Lemischka and Moore 2003). A balance between stem cell quiescence and activation is required to sustain the stem cell pool and to provide adequate numbers of mature cells to meet normal homeostatic conditions. Both the self-renewal and differentiation properties of stem cells can be altered dramatically in order to meet demands imposed by stress conditions.

In hematopoietic tissue, the most primitive stem cells are thought to be in a comparatively quiescent state. They cycle with slow kinetics that strongly correlate

\footnotetext{
${ }^{3}$ These authors contributed equally to this work.

Corresponding authors.

${ }^{4}$ E-MAIL katia.georgopoulos@cbrc2.mgh.harvard.edu; FAX (617) 726-4453. ${ }^{5}$ E-MAIL toshimi.yoshida@cbrc2.mgh.harvard.edu; FAX (617) 726-4453. Article is online at http://www.genesdev.org/cgi/doi/10.1101/gad.1642808.
}

with their long-term self-renewing potential (LT-HSC) (Morrison and Weissman 1994; Cheshier et al. 1999). Thus, maintenance of hematopoietic stem cell (HSC) activity can be compromised in two ways. On the one hand, a cell cycle block can prevent self-renewing divisions. On the other hand, prolonged cell cycle activation can lead to HSC exhaustion. This has been corroborated by studies on components of the cell cycle machinery and on signaling pathways that modulate their activity. An increase in expression of the cell cycle inhibitors $\mathrm{p} 16^{\text {Ink } 4 \mathrm{~A}}, \mathrm{p} 19^{\text {Ink } 4 \mathrm{D} / \mathrm{Arf}}$, or $\mathrm{p} 18^{\text {Ink } 4 \mathrm{C}}$ has an adverse effect on the HSC's self-renewal, presumably by restricting its entry into the cell cycle (Park et al. 2003; Yuan et al. 2004; Janzen et al. 2006; Oguro et al. 2006). Loss of the cell cycle inhibitor $\mathrm{p} 21^{\text {Cip } 1 / \text { Waf1 } 1}$ has a similar negative effect on HSC's self-renewal, but this time by allowing an increase in cycling that promotes HSC exhaustion (Cheng et al. 2000; Yu et al. 2006). In a similar fashion, continuous activation of the homeostatic Wnt, Hedgehog, and PI-3-Akt signaling pathways in the HSC in- 
creases cycling and subsequently exhausts the stem cell pool and its repopulating activity (Reya et al. 2003; Kirstetter et al. 2006; Scheller et al. 2006; Trowbridge et al. 2006; Yamazaki et al. 2006; Yilmaz et al. 2006; Zhang et al. 2006).

Interactions between the HSC and a specialized osteoblastic or vascular endothelial niche appear to be key in protecting HSC from excessive cycling and for preserving self-renewing capacity (Moore and Lemischka 2006). Signaling through Tek/Angiopoietin (Arai et al. 2004), Mpl/Tpo (Buza-Vidas et al. 2006; Qian et al. 2007; Yoshihara et al. 2007), and the TGF- $\beta$ receptor (Fortunel et al. $2000)$, as well as homophilic interactions between HSC and osteoblasts through the $\mathrm{N}$-cadherin $/ \beta$-catenin adherens complex have all been implicated in promoting anchorage to the niche, comparative quiescence, and regenerative divisions (Calvi et al. 2003; Zhang et al. 2003). Further studies on the role of a calcium-sensing receptor in HSC have also highlighted the importance of a bonederived matrix in the lodgment and retention of HSC within a regenerative endosteal niche (Adams et al. 2006). Inability of the HSC to find or interact effectively with a regenerating niche is thought to promote nonself-renewing divisions and differentiation into the downstream hematopoietic lineages.

Several genes demarcating the lineages derived from the HSC are expressed at low levels in the HSC itself, supporting the concept of lineage priming (Jimenez et al. 1992; Hu et al. 1997; Kontaraki et al. 2000; Miyamoto et al. 2002). In this model, genes required for differentiation are poised in an accessible state primed for further induction of expression and the possibility of rapid lineage fate commitment. Recent studies in embryonic stem (ES) cells have implicated the generation of a bivalent chromatin structure as a mechanism to poise key differentiation factors for expression (Bernstein et al. 2006). By this hypothesis, genes that are in an accessible chromatin but in a transcriptionally inactive state can be readily activated upon delivery of an appropriate developmental signal. Thus, a dynamic chromatin structure may provide pluripotency to somatic stem cells by maintaining the potential for gene expression required for differentiation along disparate pathways. Key to this process are nuclear regulators already expressed in the HSC that guide the differentiation outcome, possibly by supporting specific epigenetic and transcriptional changes (for review, see Georgopoulos 2002; Ng et al. 2007).

$\mathrm{Mi}-2 \beta$ is a chromatin remodeler with a SNF2-like ATPase domain that is highly expressed in the HSC and its early lymphoid, myeloid, and erythroid progeny (Kim et al. 1999). The physical association of Mi-2 $\beta$ with hematopoietic lineage-determining factors such as Ikaros and GATA-1 provides further support for a key role in hematopoietic lineage decisions (Kim et al. 1999; O'Neill et al. 2000; Rodriguez et al. 2005; Sridharan and Smale 2007). Mi-2 $\beta$ has been implicated in gene silencing in a variety of organisms through its association with histone deacetylases (HDACs), and members of the MBD family of methyl-CpG-binding proteins also present in the Nucleosome Remodeling Deacetylase (NuRD) com- plex (Tong et al. 1998; Xue et al. 1998; Zhang et al. 1998; Wade et al. 1999; Kaji et al. 2006; Linder et al. 2007). $\mathrm{Mi}-2 \beta$ can also exert a positive role in gene expression by associating with positive chromatin regulators such as methyl transferases and histone acetyltransferases (HATs) (Nakamura et al. 2002; Shimono et al. 2003; Williams et al. 2004). Recent genetic and biochemical studies have provided evidence for an antagonistic interplay between Ikaros and $\mathrm{Mi}-2 \beta$ on the $C d 4$ silencer as part of a mechanism that modulates CD4 expression during Tcell development (Naito et al. 2007).

To gain insight into the role of $\mathrm{Mi}-2 \beta$ at earlier stages of hematopoiesis, we used an inducible deletion strategy in the adult bone marrow (BM). Loss of $\mathrm{Mi}-2 \beta$ resulted in the rapid expansion of cells with the surface phenotype of long-term (LT) and short-term (ST) HSC and of erythroid progenitors. In contrast to these progenitor expansions, an early loss of myeloid progenitors was observed. At later time points, all HSC and progenitors were depleted and an accumulation of eythroid differentiation intermediates was observed. These biological effects were underscored on the one hand by a rapid down-regulation of genes implicated in self-renewal and myeloid differentiation, and on the other hand by an up-regulation of genes poised or primed in the HSC for later expression during hematopoietic lineage differentiation.

\section{Results}

Mi-2 $\beta$ deletion in the BM causes loss of lymphoid and myeloid cells and accumulation of erythroid cells

The role of Mi-2 $\beta$ in the adult hematopoietic system was tested by crossing the $M i-2 \beta^{f l / f 1}$ to the Poly (I) - Poly (C) $(\mathrm{pI} \cdot \mathrm{pC})$-inducible $\mathrm{Mx}$-Cre mouse line. BM hematopoietic lineage-positive $\left(\operatorname{Lin}^{+}\right)$and lineage-negative $\left(\mathrm{Lin}^{-}\right)$ populations were examined at different time points after Cre induction for changes in composition (as described in Materials and Methods). Three days after induction, complete $M i-2 \beta$ deletion was observed in the LSK population that encompasses HSC, defining stage I (Fig. 1A, Lin $^{-}$: LSK; SI). In contrast, deletion in the LK population that contains erythro-myeloid progenitors and in the BM $\mathrm{Lin}^{+}$hematopoietic populations was not complete until $9 \mathrm{~d}$ after induction, defining stage II (Fig. 1A, Lin' ${ }^{-}$: LK; SI, Total BM; SII; data not shown).

Concomitant with $\mathrm{Mi}-2 \beta$ deletion in the $\mathrm{Lin}^{+} \mathrm{BM}$ and $\mathrm{Lin}^{-} \mathrm{LK}$ population, a decline in granulocytes $\left(\mathrm{Mac}-1^{+} \mathrm{Gr}-\right.$ $1^{+}$, which normally represent the majority of myeloid cells in the BM, was observed (Fig. 1B, SII). Two weeks later, granulocytes were not detectable, defining stage III to IV (Fig. 1B, SIII-IV). A similar decline in pro-pre-B and immature B cells $\left(\mathrm{B} 220^{+} \mathrm{CD} 19^{+}\right)$was also seen during this period, whereas no such effect was observed in the longlived recirculating B cells $\left(\mathrm{B} 220^{\mathrm{hi}} \mathrm{CD} 19^{\mathrm{hi}}\right)$ (Fig. 1C, SIISIV).

Synchronously with the decline of short-lived myeloid and lymphoid BM populations, an increase in erythroidlineage cells was observed (Fig. 1D,E, SII-SIV). Cells with the surface phenotype and morphology of a proerythro- 
A

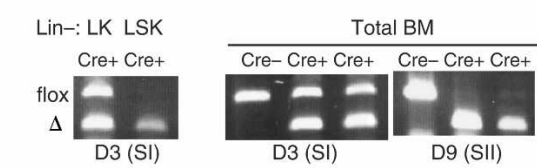

B

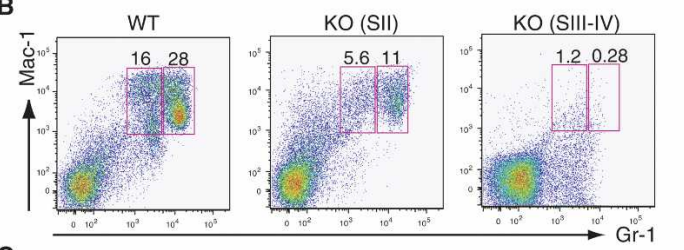

G

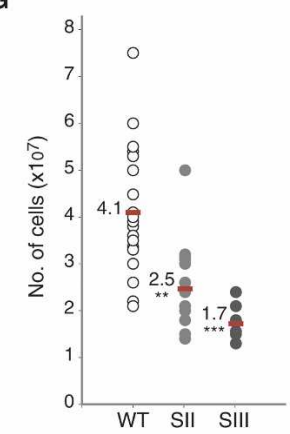

C

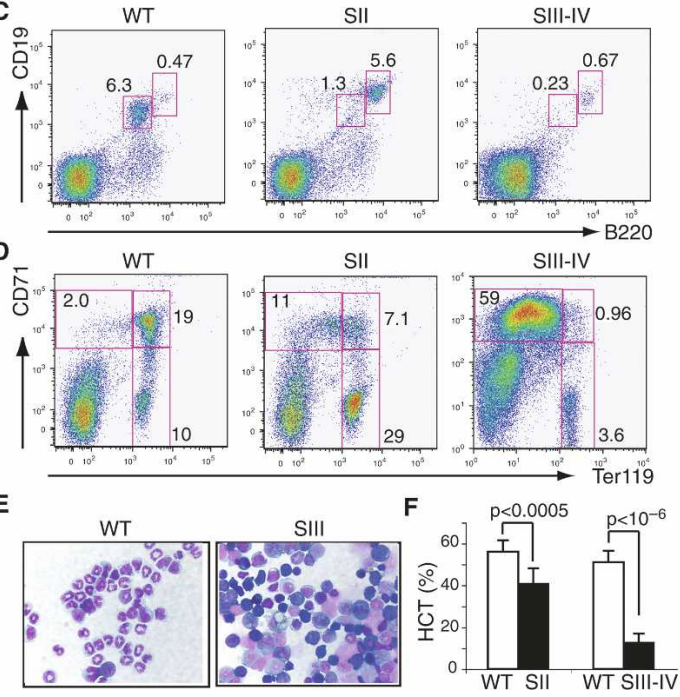

H
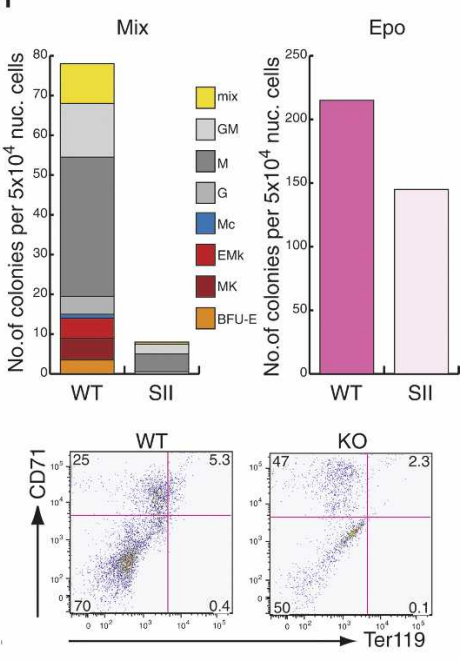

Figure 1. Loss of Mi-2 $\beta$ causes depletion of myeloid and lymphoid cells and accumulation of erythroid cells. $(A)$ PCR analysis of genomic DNA prepared from LSK and LK subsets and from total BM of wild-type (WT) and Mi- $2 \beta^{\mathrm{fl} / \mathrm{fl}}$ mice at 3 and $9 \mathrm{~d}$ post-induction. Flox and $\Delta$ designate the loxP-containing wild-type $M i-2 \beta$ and the deleted allele, respectively. Cre- and Cre+ denote the $M i-2 \beta^{f l / f 1}$; $\mathrm{Mx}-\mathrm{Cre}^{-}$and $\mathrm{Mx}-\mathrm{Cre}^{+}$mice, respectively. Myeloid $(B)$, B-cell $(C)$, and erythroid lineage $(D)$ analysis performed in the $\mathrm{Mi}-2 \beta^{\Delta / \Delta} \mathrm{BM}$ at stages II-IV after deletion is shown. Mac-1 and Gr-1 demarcate cells of the myeloid lineage, B220 and CD19 indicate cells of the B-cell lineage, and CD71 and Ter119 indicate successive erythroid lineage transitions from proerythroblast to mature erythrocyte. $(E)$ May-Giemsa staining of total BM cells at $\geq 2 \mathrm{wk}$ after $M i-2 \beta$ deletion. ( $F)$ Hematocrits of wild-type and mutants $(\mathrm{KO})$ during the stage II-IV period. (G) BM cellularity at stage II $(n=13)$ and stage III $(n=8)$ of Mi-2 $\beta$ deletion. Similarly treated wild-type littermates are shown as one group $(n=21)$. (H) Colony assays on wild-type and Mi-2 $\beta$ KO BM (SII) indicate a dramatic depletion of myeloid (Mix) but not of erythroid (Epo) progenitor activity. Mutant erythroid (CFU-E) colonies (shown as light pink) consisted of fewer and larger cells than normal colonies and were more difficult to score. This correlated with their inability to progress past the ProEB stage, which was confirmed by FACS analysis of mutant cultures for the erythroid differentiation markers CD71 and Ter119. One representative out of five independent colony assays with similar results is shown.

blast (ProEB; CD71 ${ }^{\text {hi }}$ Ter119 ${ }^{\text {lo-int }}$ ) (Socolovsky et al. 2001; Suzuki et al. 2003) that normally account for $0.5 \%-3 \%$ of the wild-type BM, comprised $>50 \%$ of the BM cellularity at $>2$ wk after $M i-2 \beta$ deletion (Fig. 1D,E, SIII-SIV). An increased number of Mi-2 $\beta$-deficient proerythroblasts was also detected in peripheral hematopoietic organs at late time points after deletion (Supplemental Fig. 1, SIII-SIV). The differentiation of proerythroblasts to the basophilic (BasoEB; CD71 ${ }^{\text {hi }}$ Ter119 ${ }^{\text {hi }}$ ) and polyerythroblast (PolyEB; CD71 ${ }^{\text {lo }}$ Ter119 ${ }^{\text {hi }}$ ) stages was impaired as indicated by a reduction of these later cell types (Fig. 1D). This is likely the cause of severe anemia and death detected among mutant mice at later stages after deletion (Fig. 1F, SIII-SIV). Consistent with the disappearance of BM myeloid and lymphoid cells, a decline in BM cellularity was also observed (Fig. 1G, SII-SIII).
The effect of $M i-2 \beta$ depletion on erythroid and myeloid differentiation was further investigated by measuring erythroid and myeloid progenitor activities in multilineage colony assays. While myeloid-producing colonies were severely reduced, erythroid colonies were readily detected but displayed altered morphology and a ProEB-like accumulation (Fig. 1H). Unfractionated BM from $\mathrm{Mi}-2 \beta^{f l / \Delta} \mathrm{Mx}-\mathrm{Cre}^{+}$or $\mathrm{Mi}-2 \beta^{+/ f 1} \mathrm{Mx}-\mathrm{Cre}^{-}$(CD45.2) mice was also transplanted into wild-type recipients (CD45.1). After establishment of stable chimerism, Mi$2 \beta$ deletion was induced. Donor contribution into the myeloid and lymphoid lineages declined rapidly, indicating that the effects of the mutation were hematopoietic cell-intrinsic (Supplemental Fig. 2).

Thus, the in vitro and in vivo differentiation properties of $\mathrm{Mi}-2 \beta$-deficient progenitors and their progeny are con- 
sistent with the changes in lineage profiles observed in Mi-2 $\beta$-deficient mice. Importantly, the altered morphology of erythroid colonies together with the significant increase in the number of mutant proerythroblasts in the BM and peripheral organs is suggestive of erythroid leukemia.

\section{Mi-2 $\beta$ is required for homeostasis in the HSC compartment}

To assess the Mi-2 $\beta$ effects at the earliest stages of the hematopoietic hierarchy, the HSC compartment (LSK; $\mathrm{Lin}^{-} \mathrm{Sca}-{ }^{+} \mathrm{Kit}^{+}$) and the erythro-myeloid progenitor $\left(\mathrm{LK}_{;} \mathrm{Lin}^{-} \mathrm{Sca}-1^{-} \mathrm{Kit}^{+}\right)$populations were also analyzed at different time points after Cre induction (Fig. 2). The LSK population contains long-term HSC (LT-HSC; Flt3-CD34-) and short-term HSC with multilineage potential (ST-HSC or MPP; Flt $3{ }^{\text {int }} \mathrm{CD} 34^{+}$and LMPP; $\mathrm{Flt}^{+}{ }^{+} \mathrm{CD} 34^{+}$) (Christensen and Weissman 2001; Adolfsson et al. 2005; Yang et al. 2005; Lai and Kondo 2006; Yoshida et al. 2006). The LK population contains erythroid ( $\left.\mathrm{LK} \mathrm{CD} 71^{+} \mathrm{CD} 34^{-}\right)$and myeloid lineage-restricted progenitors (LK CD71- ${ }^{-} \mathrm{CD} 34^{+}$) (Akashi et al. 2000; Terszowski et al. 2005).

Deletion of $M i-2 \beta$ in the LSK population was detected as early as $3 \mathrm{~d}$ (SI) after one $\mathrm{pI} \cdot \mathrm{pC}$ injection and prior to deletion in LK progenitors and $\mathrm{Lin}^{+}$hematopoietic cells (Fig. 1A). A 3.4-fold increase in the absolute number of mutant LSK was detected at this early time point (Fig. $2 \mathrm{~A}, \mathrm{SI})$. The number of mutant LSK continued to rise from the first into the second week post-induction, reaching a ninefold increase relative to wild type (Fig. 2A, SII-SIII). After the second week, a rapid decline in mutant LSK was seen to below wild-type levels, defining stage IV (Fig. 2A,B, SIV).

A further investigation into the LT-HSC and ST-HSC subsets during the LSK expansion phase was undertaken. At $9 \mathrm{~d}$ post-induction, an increase in cells with the cell surface phenotype of LT-HSC (LSK; Flt3 $\left.{ }^{-} \mathrm{CD} 34^{-}\right)$, STHSC (LSK; Flt $\left.3^{\text {int }} \mathrm{CD} 34^{+}\right)$, and LMPP (LSK; Flt $\left.3^{+} \mathrm{CD} 34^{+}\right)$ was detected (Fig. 2B,C, stage II).

Taken together, these studies indicate that $\mathrm{Mi}-2 \beta$ is likely required for homeostasis within the HSC compartment as loss of Mi- $2 \beta$ results in an apparent expansion of LSK subsets with the cell surface phenotype of LT-HSC and ST-HSC. This occurs prior to (SI-SII) any major changes in mature hematopoietic cells, which when depleted can cause a compensatory increase in progenitors. In fact, by the time mature hematopoietic cell types are lost, the LSK compartment is also depleted, suggesting a loss in self-renewing potential required for maintenance of this population.

\section{A role for Mi-2 $\beta$ in the erythroid versus myeloid lineage choice}

A similar expansion in LK progenitors was observed from stage II to III after $M i-2 \beta$ deletion, followed by a decline at stage IV (Fig. 2A,B, LK SII-IV). Furthermore,
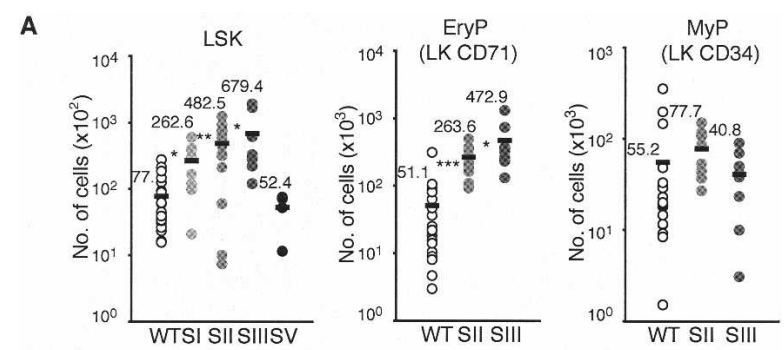

B
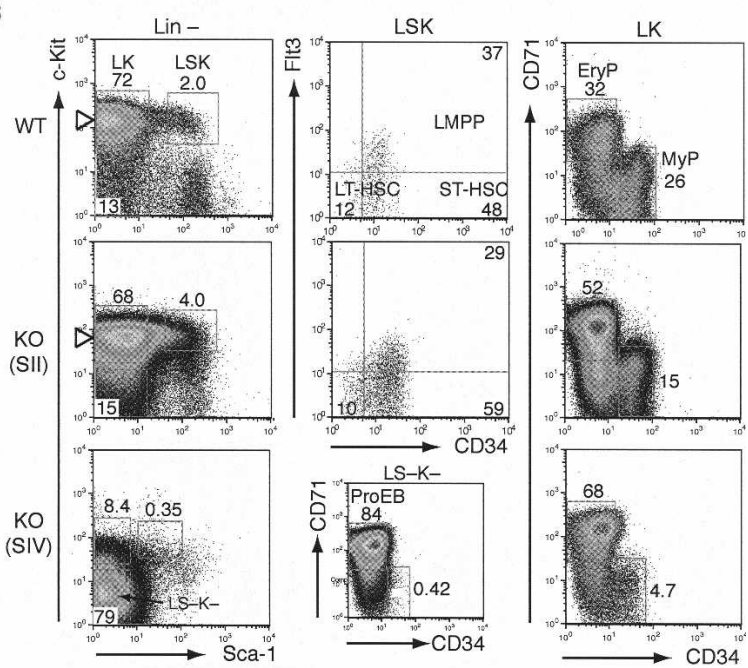

C
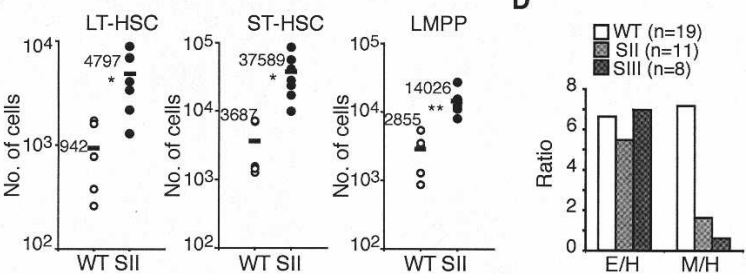

Figure 2. A dramatic expansion of Mi-2 $\beta$-deficient HSC and erythroid progenitors. (A) The absolute number of HSC (LSK), erythroid (LK CD71 $1^{+} \mathrm{CD} 34^{-}$), and myeloid (LK CD $\left.71^{-} \mathrm{CD} 34^{+}\right)$ progenitor populations is provided for stages I-III (SI, $n=8$; SII, $n=13$; SIII, $n=8$; SV, $n=4 ; 3-14 \mathrm{~d}$ ) after induction of deletion in wild type and KO. As no substantial variation in the number or profile of wild-type LSK $(n=23)$ and LK $(n=18)$ subsets was seen, these are shown collectively as one group. Each circle represents data from one animal, and the black bar indicates the mean value for each group. $\left(^{\star}\right) P<0.05 ;\left(^{\star \star}\right) P<0.005$; $\left(^{\star \star \star}\right)$ $P<0.0005$. (B) Representative profiles of wild-type and KO LSK and LK subsets at stages II and IV after induction. At stage II, the effects of $\mathrm{Mi}-2 \beta$ deletion on LT-HSC (Flt3 $\left.{ }^{-} \mathrm{CD} 34^{-}\right)$, ST-HSC $\left(\right.$ Flt $\left.3{ }^{\text {int }} \mathrm{CD} 34^{+}\right)$, and LMPP $\left(\mathrm{Flt}^{+}{ }^{+} \mathrm{CD} 34^{+}\right)$are provided. At stage IV, the accumulation of $\mathrm{LS}^{-} \mathrm{K}^{-}$ProEB in the $\mathrm{Lin}^{-}$compartment is shown. $(C)$ The absolute number of wild-type $(n=5)$ and mutant $(n=7)$ LT-HSC, ST-HSC, and LMPP is provided for stage II. For each population, the average number of cells (black bar) is provided. (D) The ratio of erythroid progenitors to HSC-LSK $(\mathrm{E} / \mathrm{H})$ or myeloid progenitors to HSC-LSK $(\mathrm{M} / \mathrm{H})$ is shown for wild type $(n=19)$ and $\mathrm{KO}$ at $1-2 \mathrm{wk}$ post-induction (SII, $n=11$; SIII, $n=8)$.

analysis of the erythroid and myeloid LK subsets revealed distinct effects of Mi- $2 \beta$ on the erythroid versus myeloid lineage choice of the HSC. A greater increase in 
the absolute number and ratio of erythroid progenitors (approximately ninefold) compared with myeloid progenitors (0.7- to 1.5-fold) (Fig. 2A,B) indicated a potential block in myeloid differentiation (Fig. 2D).

By stage IV when both mutant LSK and LK populations were declining, accumulation of a Kit ${ }^{-}$erythroid lineage differentiation intermediate expressing high levels of CD71 and accounting for the majority of $\mathrm{Lin}^{-}$cells was detected (Fig. 2B, SIV $\mathrm{LS}^{-} \mathrm{K}^{-}$). These $\mathrm{LS}^{-} \mathrm{K}^{-}$cells are contained within the ProEB (c-Kit ${ }^{-} \mathrm{CD} 71^{+}$Ter119 ${ }^{\text {lo-int }}$ ) population that accounts for the majority of the BM hematopoietic compartment at this late stage of $M i-2 \beta$ deletion (Fig. 1D).

The differentiation properties of mutant HSC were further evaluated under conditions that support multilineage differentiation in vitro. Sorted wild-type and mutant SI LSK were cultured and evaluated 2-11 d later.

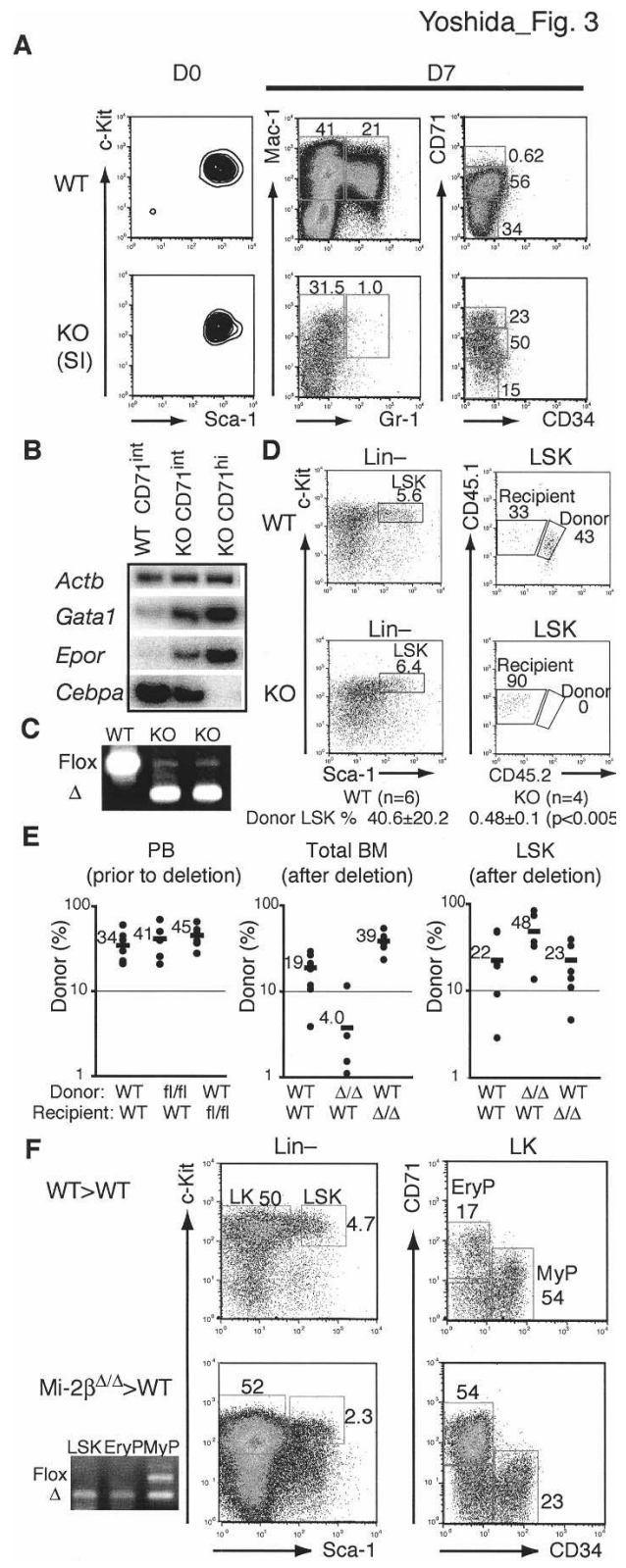

Whereas the majority of cells in the wild-type HSC cultures expressed markers of myeloid differentiation $\left(\mathrm{Macl}^{+} \mathrm{Grl}^{-}\right.$and $\left.\mathrm{Macl}^{+} \mathrm{Grl}^{+}\right)$, a smaller fraction of mutant cells did so $\left(\mathrm{Macl}^{+} \mathrm{Grl}^{-}\right)$(Fig. 3A-C). Many of the mutant cells expressed high levels of CD71, which is normally up-regulated during erythroid-lineage differentiation. The $\mathrm{CD} 71^{\mathrm{hi}}$ population, produced only in mutant LSK cultures, expressed predominantly erythroid differentiation markers (Gata1 and Epor). Cells with intermediate levels of CD71 produced by both wild-type and mutant LSK cultures were also examined. In the wild type, these cells expressed predominantly myeloidlineage factors (i.e., Cebpa), whereas in the mutant, they expressed both myeloid and erythroid factors at similar levels (Fig. 3A-C). Thus, upon Mi-2 $\beta$ deletion, HSC acquire a bias for erythroid lineage differentiation that is apparent under both in vivo and in vitro conditions.

\section{Cell-intrinsic effects of Mi-2 $\beta$ deficiency on HSC and progenitors}

The properties of mutant LSK were further evaluated in vivo in a series of transplantation assays. First, transplantation of 5000 SII-Mi-2 $\beta^{\Delta / \Delta}$ LSK into wild-type sublethally irradiated recipients failed to reveal any contribution to the LSK or to any other $\mathrm{Lin}^{-}$or $\mathrm{Lin}^{+}$populations (data not shown). In contrast, 5000 wild-type LSK treated in a similar fashion provided long-term $\mathrm{Lin}^{-}$and $\mathrm{Lin}^{+}$contributions. Since cycling HSC do not efficiently home to the BM (Bowie et al. 2006), we also transplanted

Figure 3. In vitro and in vivo differentiation properties of Mi$2 \beta$-deficient HSC. (A) Sorted (DO) wild-type and mutant LSK from stage I were cultured under multilineage differentiation conditions for $7 \mathrm{~d}(\mathrm{D} 7)$ and then analyzed for surface expression of myeloid $\left(\mathrm{Macl}^{+} \mathrm{Grl}^{+}\right)$and erythroid $\left(\mathrm{CD} 71^{\text {hi }}\right)$ markers and for lineage-specific RNAs. $(B)$ For the RNA studies, semiquantitative RT-PCR was performed for representative erythroid (Gata1 and Epor) and myeloid (Cebpa) lineage genes on sorted wild-type and KO CD $71^{\text {int }}$ cells and KO CD $71^{\text {hi }}$ cells from day 7 cultures. (C) PCR analysis of genomic DNA confirmed the respective wild-type or mutant origin of these cells. One representative out of three independent experiments with similar outcomes is shown. (D) One representative plot of donor (CD45.1/CD45.2) contribution of 5000 wild-type $\left(M i-2 \beta^{f l / f 1}\right)$ and mutant $(M i-$ $\left.2 \beta^{\Delta / \Delta}\right)$ LSK deleted $24-36 \mathrm{~h}$ after transplantation is shown at 2 wk after treatment. The average donor percentage of contribution of wild-type $(n=6)$ and mutant $(n=4)$ experiments is indicated. $(E)$ The wild-type $\left(M i-2 \beta^{f 1 / f 1}\right)$ and mutant $\left(M i-2 \beta^{\Delta / \Delta}\right)$ LSK contributions were also examined after stable chimerism was first established. Donor contribution (\% CD45.2) before and after $\mathrm{Mi}-2 \beta$ deletion in the peripheral blood (PB), BM lineagepositive (Total BM), and LSK populations was determined by flow cytometry (WT $>\mathrm{WT}, n=8$; Mi- $2 \beta^{\mathrm{fl} / \mathrm{fl}}>\mathrm{WT}, n=5$; Mi$2 \beta^{\Delta / \Delta}>\mathrm{WT}, n=5$; WT $\left.>\mathrm{Mi}-2 \beta^{\Delta / \Delta}, n=7\right)$. The average donor contribution (black bar) in each group is indicated. $(F)$ For three of the $\mathrm{Mi}-2 \beta^{\Delta / \Delta}>$ WT recipients shown in $E$, a major mutant contribution in LSK and LK erythroid progenitors $\left(\mathrm{CD} 71^{+}\right)$but not in the LK myeloid $\left(\mathrm{CD} 34^{+}\right)$progenitors was independently confirmed by PCR analysis of genomic DNA from sorted populations (as described in Fig. 1A). 
$M i-2 \beta^{f l / f 1} ; \mathrm{Mx}-\mathrm{Cre}^{+}$LSK (CD45.1/45.2 into CD45.1 recipients) and induced their deletion 24-36 h later. Again, no significant mutant donor contribution was observed in the LSK and its progeny 5-21 d after induction. In contrast, a major donor contribution was observed with wild-type as well as with uninduced $\mathrm{Mi}-2 \beta^{f 1 / f 1} ; \mathrm{Mx}-\mathrm{Cre}^{+}$ LSK (Fig. 3D; data not shown).

Since 24-36 h may not be a sufficient time to allow stable engraftment of HSC, we also tested the effect of Mi-2 $\beta$ deletion after stable chimerism was established. For this purpose, $2000 \mathrm{Mi}-2 \beta^{f l / f 1}$; $\mathrm{Mx}-\mathrm{Cre}^{+}$or $\mathrm{Mi}-2 \beta^{f l / f 1}$; $\mathrm{Mx}-\mathrm{Cre}^{-}$LSK were transplanted into sublethally irradiated $\mathrm{Mi}-2 \beta^{f l / f 1} ; \mathrm{Mx}-\mathrm{Cre}^{+}$or $\mathrm{Mi}-2 \beta^{f l / f 1} ; \mathrm{Mx}-\mathrm{Cr} e^{-}$recipients. Four to six weeks after transplantation, Mi-2 $\beta$ deletion was induced in mice with $>20 \%$ donor contribution in peripheral blood (Fig. 3E, PB prior to deletion). Donor as well as recipient contributions to the $\mathrm{Lin}^{+}$and LSK populations were analyzed $9 \mathrm{~d}$ after deletion (Fig. 3E,F). A rapid decline in donor-derived myeloid and lymphoid cells $\left(\mathrm{CD}^{4} 5^{+}\right)$was observed (Fig. 3E, Total BM; Mi-2 $\left.\beta^{\Delta / \Delta}>\mathrm{WT}\right)$. However, the LSK population of several wild-type recipient mice was predominantly of mutant origin (Fig. 3E, LSK; Mi- $2 \beta^{\Delta / \Delta}>$ WT). LSK and progenitors were also sorted from several recipients and analyzed for Mi-2 $\beta$ deletion on genomic DNA (Fig. $3 \mathrm{~F}, \mathrm{Mi}-2 \beta^{\Delta / \Delta}>\mathrm{WT}$ ). This type of analysis confirmed a major mutant contribution into LSK and erythroid progenitors but not in myeloid progenitors. Interestingly, although the mutant microenvironment did not support a greater expansion of wildtype LSK, it did support a greater expansion of $\mathrm{Lin}^{+}$cells (Fig. 3E, LSK and Total BM in WT $>\mathrm{WT}$ and $\mathrm{WT}>\mathrm{Mi}-$ $\left.2 \beta^{\Delta / \Delta}\right)$.

Taken together, these studies indicate that the rapid expansion of mutant HSC and their limited differentiation into the erythroid lineage is cell-intrinsic and can occur outside a mutant BM microenvironment. They also indicate that cycling mutant HSC are unable to home to or engage with a regenerative BM niche and are rapidly lost.

Loss of quiescence and increase in cycling in Mi-2 $\beta$-deficient HSC and MPP

We next examined the cell cycle and apoptotic properties of mutant HSC and its progeny as potential mechanisms that underlie their rapid expansion and exhaustion. An increase in cycling LSK was already apparent at the earliest stage of Mi-2 $\beta$ depletion (Fig. 4A, SI). During the expansion phase of mutant LSK, a twofold increase in proliferation was detected on average (Fig. 4A,B, SII and SIII). No significant increase in the proliferation of mutant erythroid-restricted (or myeloid-restricted) progenitors, the majority of which are normally in cycle, was observed (Fig. 4B, SII and SIII). The quiescent $\left(\mathrm{G}_{0}\right)$ subset of LSK responsible for long-term multilineage repopulation was also evaluated using Pyronin Y staining. Quiescent LSK (Pyronin Y negative) were reduced (greater than fourfold) upon Mi-2 $\beta$ deletion (Fig. 4C, SII-SIII). A twofold to threefold increase in apoptosis of mutant LSK and LK populations was observed (Fig. 4D, SII-SIII).
A
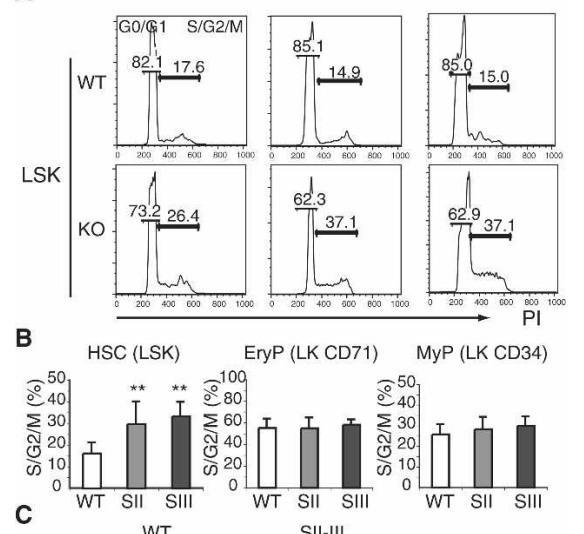

C

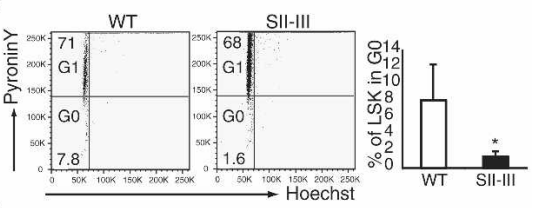

D

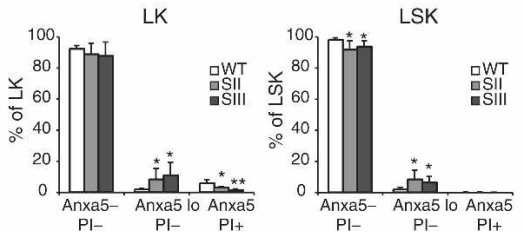

Figure 4. Loss of quiescence and increase in cycling and apoptosis in Mi-2 $\beta$-deficient HSC. The cell cycle distribution $\left(\mathrm{G}_{0} /\right.$ $\mathrm{G}_{1}$ and $\mathrm{S} / \mathrm{G}_{2} / \mathrm{M}$ ) of sorted LSK and erythroid and myeloid LK subsets from wild-type $\left(M i-2 \beta^{f l / f 1}\right)$ and mutant $\left(M i-2 \beta^{\Delta / \Delta}\right) \mathrm{BM}$ at stages I-III was revealed by PI staining. Representative cell cycle profiles for the LSK are shown in $A$. The percentage of cells in the $S / G_{2} / M$ phase of the cell cycle and the statistical analysis of all experiments are shown in $B$. Wild type, $n=9$; KO SII, $n=9$; and SIII, $n=3 .\left(^{\star \star}\right) P<0.005$. $(C)$ To further distinguish the $\mathrm{G}_{0}$ from $\mathrm{G}_{1}$ content of wild-type and KO LSK at stage II, PyroninY/ Hoechst staining was used. Representative flow cytometry profiles are shown on the left. Statistical analysis for $\mathrm{G}_{0}$ distribution of all these studies is shown on the right. Wild type, $n=4$; KO SII-SIII, $n=7$. (D) The apoptotic index of wild-type and KO LSK at stages II-III and their progeny was revealed by Annexin $\mathrm{V}$ and PI staining (Annexin $\left.\mathrm{V}^{\mathrm{lo}} \mathrm{PI}^{-}\right)$. Wild type, $n=7$; KO SII, $n=6$; and SIII, $n=5 .\left(^{\star}\right) P<0.05 ;\left(^{\star \star}\right) P<0.005$.

Thus, depletion of Mi-2 $\beta$ increases the number of cycling cells in the HSC compartment. The cycling mutant HSC appear unable to resume a quiescent status required for maintenance. Furthermore, they display an increased apoptotic rate, which may contribute to their eventual depletion at stage IV.

HSC retain the majority of their transcriptional profile upon loss of Mi-2 $\beta$

To begin to address potential changes in gene expression in the HSC and its early progeny that may be responsible for changes in their properties, a global gene expression analysis was performed on wild-type and mutant LSK, erythroid, and myeloid progenitors at the earliest time point of $M i-2 \beta$ deletion in all of these populations (Supplemental Fig. 3, stage II). 
Gene array analysis of stage II Mi-2 $\beta$-deleted LSK identified 356 unique genes that were down-regulated and 347 unique genes that were up-regulated (Fig. 5A; Supplemental Table 1, 436 gene-specific probe sets down-regulated; Supplemental Table 2, 433 gene-specific probe sets up-regulated). This relatively small number of changes indicated that Mi- $2 \beta$ does not play a global role in gene expression in the LSK. Unbiased clustering analysis demonstrated that the mutant LSK has a gene expression profile that is most similar to the wild-type LSK and distinct from that of the LK CD71 erythroid progenitors (Fig. 5B,C). Importantly, the Mi-2 $\beta$-deficient LSK retained the majority (three-fourths) of a gene expression profile that is specific for wild-type LSK (Fig. $5 \mathrm{~A}, \mathrm{~B}, 354$ out of 472 ). This LSK-specific signature was deduced by comparative analysis of the wild-type LSK data sets with the wild-type LK erythroid and myeloid progenitor data sets and exhibits significant overlap with previously published LT-HSC databases (Ivanova et al. 2002; Ramalho-Santos et al. 2002). Finally, Mi-2 $\beta$-deficient LSK did not appear to acquire a gene expression profile indicative of rapid restriction into an erythroid- or myeloid-committed progenitor (Fig. 5C; data not shown).
Positive regulation of HSC-specific transcriptional signatures by Mi-2 $\beta$

Among the 356 genes that are dependent on $\mathrm{Mi}-2 \beta$ for expression in the LSK population, changes clustered in two major groups (groups 1 and 2 in Fig. 6A). The first group of genes is specifically expressed in the LSK and represents one-fourth of the LSK-specific signature shown in Figure 5, A and B (118 out of 472). Several members of this LSK-specific group are known or are strong candidates for regulating HSC self-renewal and homeostasis (Fig. 6B; Supplemental Figs. 4, 5). The HSC niche interaction-regulating receptors Tek (Arai et al. 2004) and Mpl (Buza-Vidas et al. 2006; Qian et al. 2007; Yoshihara et al. 2007), the Kit receptor (Sharma et al. 2006; Bowie et al. 2007) expressed in HSC and its progeny, and the metalloendopeptidase inhibitor Lxn (Liang et al. 2007) are examples of previously established selfrenewal regulators that belong to this group. Other members of this group promote cell cycle arrest and are potential regulators of self-renewal. The modulators of TGF $\beta$ signaling Ltbp3, of Rho-Ras signaling Dmxl2, the cytokine receptor $I 117 \mathrm{re}$, the transglutaminase $\mathrm{Tgm} 2$,

A

Figure 5. The Mi-2 $\beta$-deficient HSC retain their transcriptional identity. $(A, l e f t)$ A venn diagram displaying the overlap between genes down-regulated in KO LSK and genes that are specifically expressed in wild-type LSK. This LSK-specific group of genes (transcriptional signature) was deduced by comparative analysis of the wild-type LSK data sets to the wild-type LK erythroid and myeloid progenitor data sets and exhibits significant overlap with previously published LT-HSC databases (Ivanova et al. 2002; Ramalho-Santos et al. 2002). This analysis indicates that the majority of the LSK-specific (LSK-sp) transcriptional signature (354 out of 472 gene-specific probe sets) remains intact in the KO. However, functionally important differences (118 out of 472 gene-specific probe sets) between wildtype and KO LSK are also revealed. (Right) Overlap between the wild-type LSK-specific group of genes and genes up-regulated in the KO LSK. A small subset of wild-type LSK-specific genes was also upregulated in the absence of $\mathrm{Mi}-2 \beta$ (23 out of 472 ). (B) Unbiased clustering of wild-type and KO LSK (HSC), LK CD34 (myeloid), and LK CD71 (erythroid) populations according to the LSK-specific transcriptional signature (as in $A$ ). (C) Unbiased clustering of KO LSK with wild-type LSK, LK CD34, and LK CD71 subsets according to an erythroid progenitor-specific group of genes (LK CD71specific signature) deduced by comparative analysis of wild-type LSK and LK data sets. Unbiased clustering analysis from both $B$ and $C$ indicates that $\mathrm{KO}$ LSK has a gene expression profile that is most similar to its wild-type counterpart and distinct from those of its LK erythroid or myeloid progeny (data not shown).
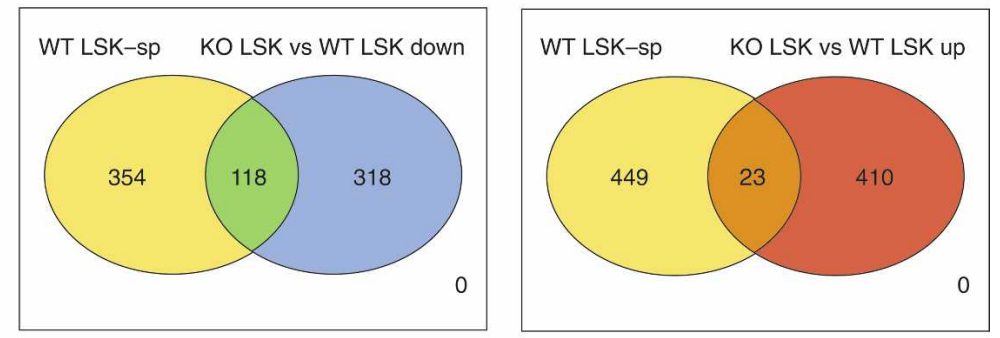

B
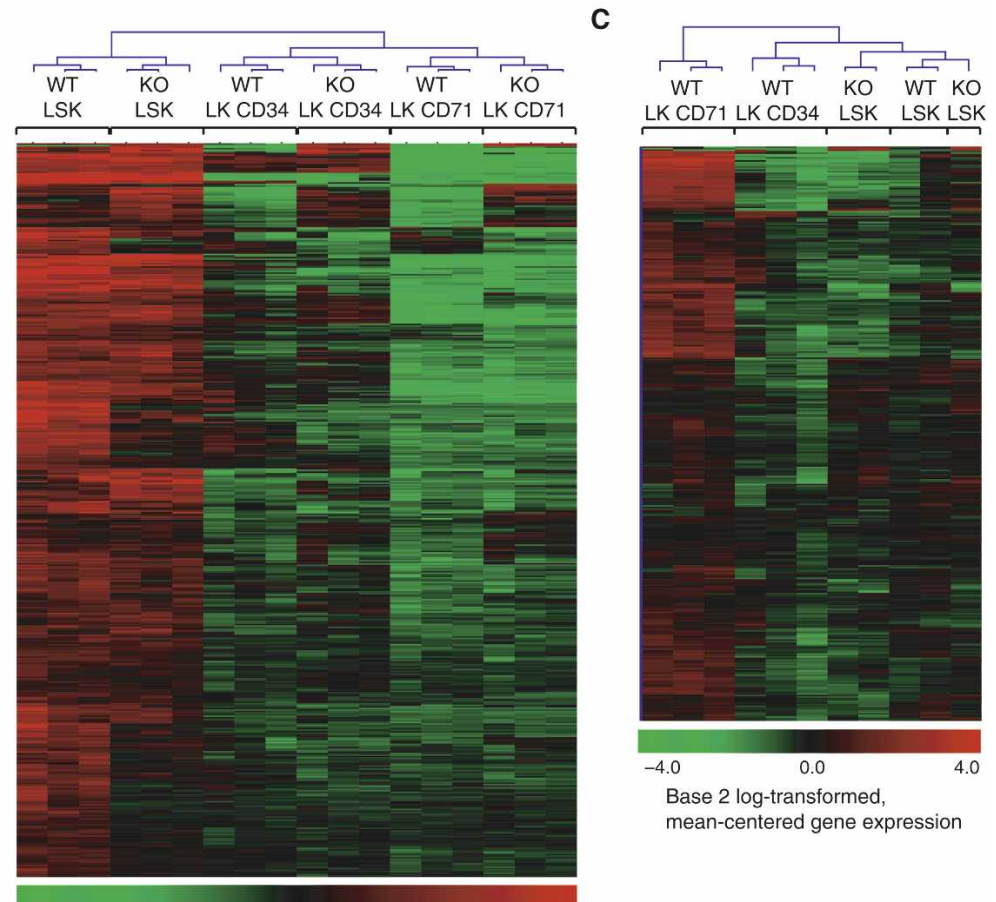

$-3.0$

0.0

3.0

Base 2 log-transformed, mean-centered gene expression 
A

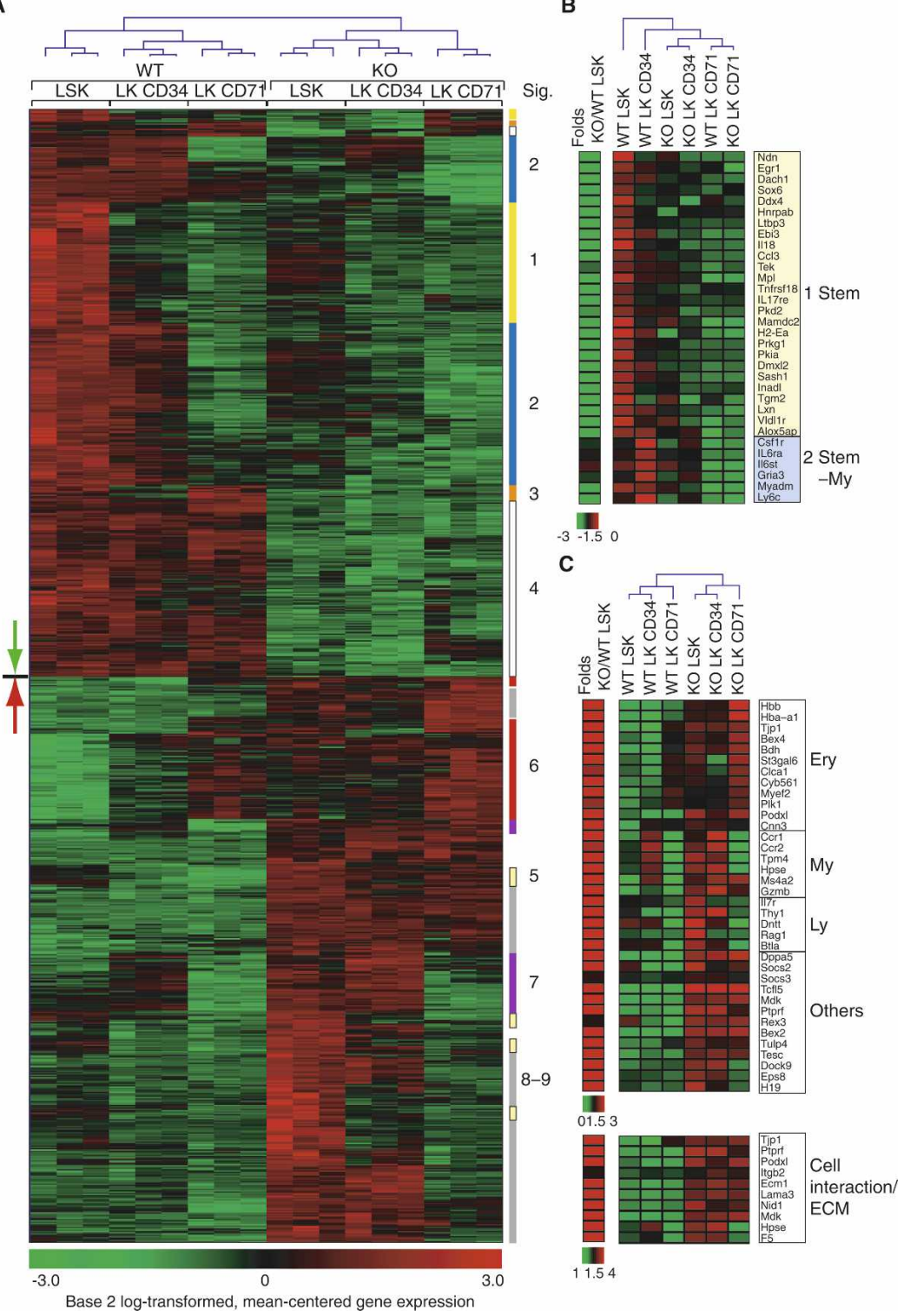

Figure 6. Specific effects of Mi-2 $\beta$ deficiency on the gene expression profiles of the HSC. $(A)$ Unique genes deregulated in the KO LSK (356, green down arrow; 347, red up arrow) and clustered in a hierarchical manner across wild-type and KO LSK and LK segregate into distinct transcriptional groups. The down-regulated genes segregate into LSK-specific (group 1; Stem: yellow), LSK and LK CD34-specific (group 2; StemMy, blue), LSK and LK CD71-specific (group 3; Stem-Ery, orange), and expressed in all (group 4; All, white) subsets. The up-regulated genes fall into LSK-specific (group 5: Stem, yellow), LK CD71-specific (group 6; Ery, red), LK CD34-specific (group 7; My, purple), and neg-low in all (group 8/-9, gray) subsets. (B) Representative genes from groups 1-4 that are most relevant to the HSC's expansion and differentiation phenotypes are presented. $(C)$ Representative genes "overtly or cryptically primed" for expression in the erythroid (Ery), myeloid (My), and lymphoid (Ly) lineages as well as others are shown. A notable group of cell interaction/ECM genes upregulated in KO LSK is also shown. the nuclear regulators $N d n$ and Dach1, the RNA helicase and germ cell-determining factor $D d \times 4$, the signaling and scaffolding molecules Pkd2 and Sash1, and the 5-lipoxygenase-activating protein Alox 5 ap regulating ROS are such examples. The cytokine Ebi3 (IL-27), with diverse immunoregulatory (Colgan and Rothman 2006), anti-tumor, and anti-metastatic (Shimizu et al. 2006) activities, is also in this group of genes.

To examine whether the down-regulation of members of the LSK-specific group was directly related to loss of Mi-2 $\beta$, we tested their expression upon the first indication of Mi-2 $\beta$ deletion in the LSK (Supplemental Fig. 4A, SI). Expression of several of these LSK-specific genes was already reduced at this earliest time point of $M i-2 \beta$ deletion, suggesting their direct dependence on this factor. Examples of such potential direct targets of Mi-2 $\beta$ are $\mathrm{Mpl}, \mathrm{Ndn}, \mathrm{Mamdc2}$, Tgm2, and Ebi3 (IL-27). Others, like Kit and Cond2, although reduced later (Supple- mental Fig. 4B), were not deregulated at this early time point.

The second group of down-regulated genes belongs to a transcriptional signature considered to be "primed" in the HSC (Mansson et al. 2007). Lack of expression of several genes from this stem-myeloid-specific group (Stem-My; group 2) in the mutant LSK or lack of subsequent up-regulation in myeloid progenitors is expected to impede myeloid differentiation. Such examples are the early myeloid lineage-inducing cytokine receptors Csf1r, Il6Ra, and Il6st (common chain for both IL-6 and IL-11 receptors) and the nuclear regulator Egr1 (Fig. 6B; Supplemental Fig. 4A,B; de Haan and Van Zant 1997). A third group consisting of a small number of erythroidspecific (Stem-Ery; group 3) genes primed for expression in the HSC was also down-regulated (Fig. 6A). None of these appear to be critical for erythroid lineage commitment. 
Thus, two major subsets of HSC-specific and HSCprimed myeloid-specific genes are dependent on $\mathrm{Mi}-2 \beta$ for their expression in the LSK compartment. Deregulation of genes in these two subsets may underlie the loss of self-renewal and multilineage differentiation displayed by the mutant HSC and its MPP progeny.

\section{Negative regulation of multilineage transcriptional priming by Mi-2 $\beta$}

Of the 347 genes that depend on Mi-2 $\beta$ for repression in the LSK compartment, the majority are normally upregulated at later stages of hematopoiesis (Fig. 6A). These fall into two categories; one that is already expressed at low levels in the LSK population or its early erythroid or myeloid progeny and can be considered "primed" (groups 5,6 , and 7), and a second that is "poised" for expression later in the lineage, but whose "cryptically primed" state in the LSK is only revealed when Mi- $2 \beta$ is mutated, resulting in their expression (groups 8 and 9). Both of these categories of genes, primed and poised, are repressed by Mi-2 $\beta$. Examples of such negatively regulated loci primed or poised for expression are Hba-a1 and Hbb-b1 of the erythroid lineages (Ery); Ccr1 and Ccr2 of the myeloid lineage (My); and Thy1, Dntt, and Rag1 of the lymphoid lineage (Ly) (Fig. 6C). Interestingly, expression of a significant number of ECM adhesion molecules was also increased.

Genes that are not normally expressed in the adult hematopoietic lineages were also induced in the mutant HSC. The ES cell marker Dppa5; the embryonic $\beta$ - and $\alpha$-globins $H b b-y, H b b-b h 1$, and $H b a-X$; the epithelial cytokine $M d k$; and the testis-specific E-box-binding protein Tcf15 are such examples (Fig. 6C; Supplemental Fig. $4 \mathrm{C})$. Several of these primed-poised genes were also rapidly up-regulated upon loss of Mi- $2 \beta$ in the HSC, suggesting their direct regulation by this chromatin factor (Supplemental Fig. 4A). Further functional categorization of the up-regulated genes according to the Gene Ontology database revealed an overrepresentation of genes involved in protein metabolism and cell cycle regulation (Supplemental Fig. 6, UP), correlating with the increased cycling properties of mutant LSK. In contrast, functional categorization of down-regulated genes revealed an overrepresentation of genes involved in organic and fatty acid metabolism (Supplemental Fig. 6, DOWN).

Importantly, loss of Mi-2 $\beta$ at later stages of hematopoietic lineage differentiation does not induce expression of the majority of genes derepressed upon Mi-2 $\beta$ deletion in the LSK. For example, loss of Mi-2 $\beta$ at the DN3 stage of T-cell development causes up-regulation of a cohort of genes, which in their majority are distinct from the ones deregulated in the HSC and early hematopoietic progenitors (Supplemental Fig. 7; Supplemental Table 3). This puts forward the hypothesis that Mi- $2 \beta$ is involved in the repression of genes that are "primed or poised" in the HSC, but is not required for maintenance of their silenced state acquired later upon lineage commitment.

\section{A direct role of $\mathrm{Mi}-2 \beta$ in the regulation of lineage priming in progenitors}

To further examine the hypothesis that Mi- $2 \beta$ is a direct regulator of lineage priming in the early hematopoietic hierarchy, we examined its direct association and effects on the chromatin state of two genes representative of priming of disparate hematopoietic lineages in the HSC. $H b b-b 1$, an erythroid lineage gene, and Rag1, a lymphoid lineage gene, both reported as primed in the HSC (Miyamoto and Akashi 2005; Mansson et al. 2007), were rapidly up-regulated upon loss of Mi-2 $\beta$ (Fig. 7A; Supplemental Fig. 4A). Chromatin immunoprecipitation (ChIP) analysis of hematopoietic progenitors containing HSC revealed a direct and specific association of $\mathrm{Mi}-2 \beta$ with the promoters of Hbb-b1 and Rag1 (Fig. 7B). No association was detected with an upstream region of $H b b-b 1$ (IVR) or an upstream region (UP) of the Rag1 promoter that were used as negative controls. Association of Mi-2 with the Hbb-b1 promoter was also detected in ES cells and with the Rag1 promoter and the $C d 4$ silencer, a previously established target, in thymocytes (Naito et al. 2007). Unlike $H b b-b 1, M i-2 \beta$ enrichment at the promoter of Rag1 was not detected in progenitors depleted of LSK (data not shown), indicating Mi-2 $\beta$ 's role in the regulation of the Rag locus in progenitors with potential for lymphoid differentiation.

The effect of loss of Mi-2 $\beta$ on the chromatin state of the $H b b-b 1$ and Rag1 promoters was examined. A small but reproducible increase (approximately twofold) in the permissive methylation at $\mathrm{K} 4$ of $\mathrm{H} 3$ and acetylation of $\mathrm{H} 3$ was detected over the $H b b-b 1$ and the Rag1 promoter in the LSK compartment, correlating with an increase in expression of these genes in this population (Fig. 7A,C). A greater increase in meH3K4 and $\mathrm{AcH} 3$ was detected over the Hbb-b1 promoter in mutant erythro-myeloid progenitors $(\mathrm{LK})$, correlating with the further increase in Hbb-b1 expression in this population (Fig. 7A,C). No change in permissive histone modifications at the Rag1 promoter was detected in erythro-myeloid progenitors, correlating with a lack of increase in Rag1 expression in this mutant population (Fig. 7A,B). We also tested for any potential effects on the restrictive meK27H3 modification, but no appreciable changes were observed (data not shown). Also, no significant change in H3 occupancy at the promoters of $H b b-b 1$ or Rag1 was detected in progenitors upon Mi- $2 \beta$ deletion (data not shown).

Thus, Mi-2 $\beta$ directly associates with at least two lineage-primed genes in multipotent progenitor populations. This association is necessary to keep these genes in a chromatin-restrictive and transcriptionally quiescent state, as upon Mi-2 $\beta$ removal a permissive chromatin state and gene expression are rapidly induced.

\section{Discussion}

Our studies reveal that self-renewal and multilineage differentiation potential, the defining properties of the HSC, are critically dependent on the chromatin remodeler Mi-2 $\beta$ (Fig. 8A). The reciprocal number of positive 

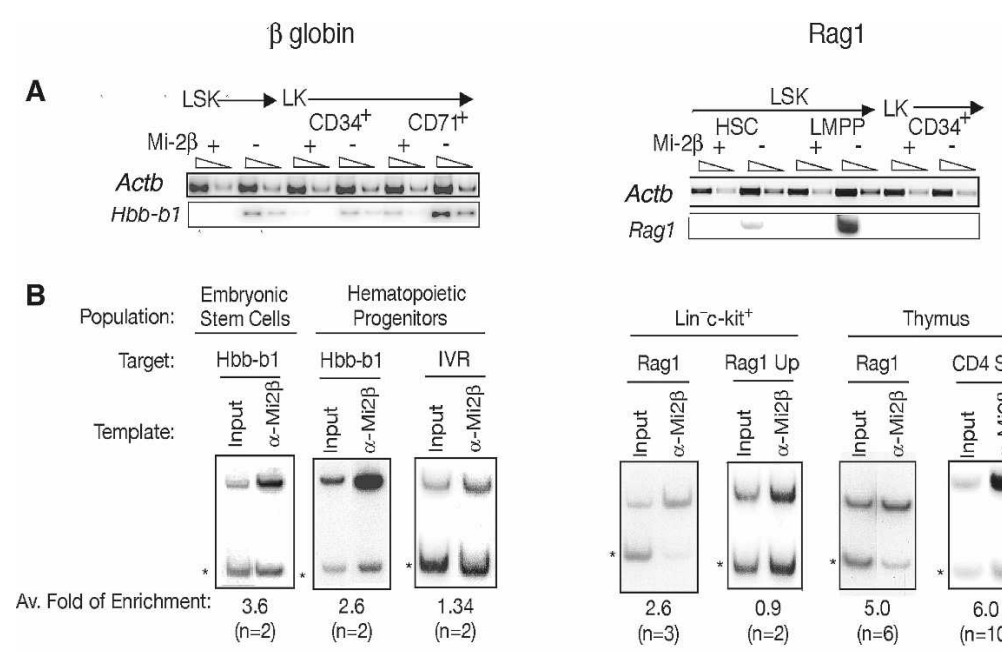

C
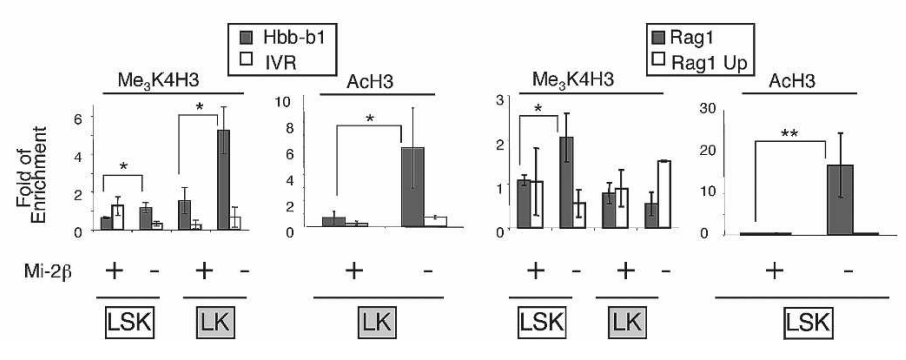

Figure 7. A direct role of Mi-2 $\beta$ in lineage priming in hematopoietic progenitors. (A) $H b b-b 1$, an erythroid lineage gene, and Rag1, a lymphoid lineage gene, both reported as primed in the HSC (Miyamoto and Akashi 2005; Mansson et al. 2007), were rapidly up-regulated upon loss of Mi-2 $\beta$ in LSK and LK subsets (see also Supplemental Fig. 4A). $(B)$ ChIP analysis for Mi-2 $\beta$ was performed at the promoters of $H b b-b 1$ and Rag1, and upstream regions of $H b b-b 1$ (IVR) and Rag-1 (Rag1 UP) and the Cd4 silencer in hematopoietic progenitor populations $(+\mathrm{HSC})$, in ES cells, and in thymocytes (thymus). ChIPs were analyzed by multiplex PCR of test (Hbb-b1, IVR, Rag1, Rag1 UP, and CD4 Sil) and internal control regions (star). The average fold enrichment ratio relative to the input ratio deduced from all experiments and the number of independent chromatin preparations used for these studies is shown at the bottom of each panel. PCR analysis of ChIPs was repeated at least twice. (C) Permissive meH3K4 and AcH3 histone modifications were examined at the promoters of the $H b b-b 1$ and Rag1 genes and at control regions (IVR and Ragl UP) in LSK and LK progenitor populations isolated from wild-type $(\mathrm{Mi}-2 \beta+)$ and $\mathrm{KO}(\mathrm{Mi}-2 \beta-)$ mice. The calculated enrichment ratio relative to input ratio is provided for each panel. Two independent LSK and LK chromatin preparations were used for these studies, and each was analyzed twice. The only exception is the AcH3 study on the Rag1 locus, where one ChIP was analyzed twice. $\left({ }^{\star}\right) P<0.05$; $\left(^{\star \star}\right)$ $P<0.005$. and negative changes in gene expression that occur upon loss of Mi-2 $\beta$ within the HSC compartment strongly correlate with the ensuing biological phenotypes (Fig. 8B). Together, the cellular and molecular studies described here reveal a dual role for this chromatin regulator in the early hematopoietic hierarchy, possibly arising through its interactions with functionally disparate nuclear factors on HSC-specific and lineage-primed genes (Zhang et al. 1998; Nakamura et al. 2002; Shimono et al. 2003; Williams et al. 2004; Naito et al. 2007).

Shortly after $\mathrm{Mi}-2 \beta$ deletion, an unprecedented, ninefold expansion of cells with an HSC-specific cell surface phenotype was observed that was supported by a reciprocal increase in dividing cells and decrease in quiescent cells in this compartment. The observed twofold increase in cycling cells may not be sufficient to account for the greater increase in absolute number that occurs within a short time after deletion. Given that the apoptosis rate is not decreased, this is likely due to a change in cell cycle kinetics. Thus, loss of Mi- $2 \beta$ not only increases the number of cycling HSC-MPP but may also accelerate their cycling rate. Notably, the Mi-2 $\beta$ deletion-induced expansion of HSC-like cells is short-lived, as these disappear at later time points after deletionmost likely due to an increased apoptotic rate. Significantly, the expansion and differentiation properties of mutant HSC and their progeny are cell-intrinsic and are not dependent on a mutant environment, indicating that changes in the molecular machinery responsible for these effects occur from within.
Of the genes dependent on Mi- $2 \beta$ for their expression, a prominent subset is HSC-specific. Some of these downregulated genes have already been implicated in stem cell maintenance by promoting niche interactions (i.e., Tek and Mpl), while others were reported as negative regulators of cell proliferation (i.e., Ltbp3/TGF $\beta$ pathway, $N d n$, and $P k d 2$ ). Down-regulation of key membrane receptors and signaling pathways responsible for keeping cells quiescent can readily account for the increase in cycling and expression of cell cycle-dependent genes within the mutant HSC population. Interestingly, an increase in the expression of a significant number of ECM-adhesion-cytoskeletal and associated signaling molecules was also observed. Aberrant expression of EC$\mathrm{M}$-adhesion molecules has been reported in cancer cells that bypass normal environmental cues and controls by generating their own microenvironment to support their expansion (Pupa et al. 2002). It will be important to determine whether $\mathrm{Mi}-2 \beta$ deletion-induced changes in the expression of such genes is permissive to the rapid expansion and maintenance defects that are triggered upon deregulation of known homeostatic factors (i.e., Tek and Mpl) in the Mi-2 $\beta$-depleted HSC. In the future, studies on Mi- $2 \beta$ HSC-specific targets may provide us with a comprehensive view of the pathways that act in concert to ensure a life-long supply of HSC.

The increase in the Mi-2 $\beta$-deficient HSC population occurs simultaneously with an increase in erythroid-restricted progenitors of a similar magnitude. In contrast, myeloid-restricted progenitors show a progressive de- 
A

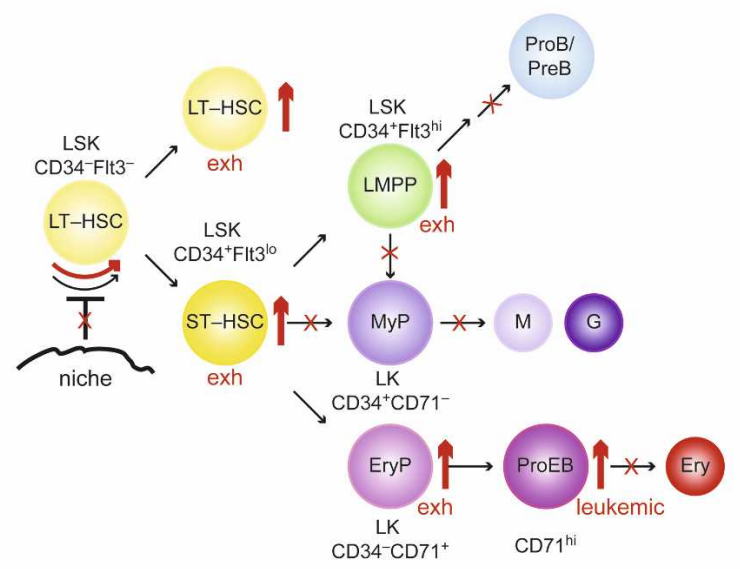

B

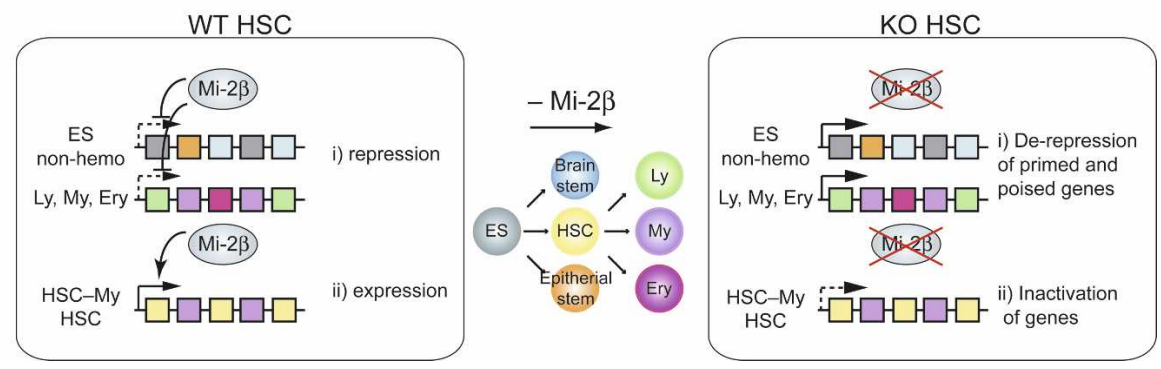

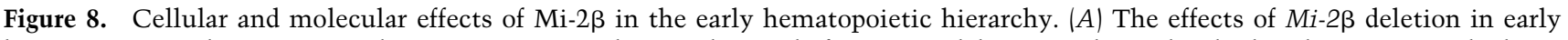
hematopoiesis. The increase in hematopoietic populations detected after Mi-2 $\beta$ deletion is shown by thick red up arrows. Blocks in differentiation or in potential HSC interaction with a regenerative niche are depicted with red crosses. Increase in the cycling of mutant HSC is indicated by a red curved arrow. The eventual exhaustion (exh) of HSC and progenitors at later stages of $M i-2 \beta$ deletion and accumulation of potentially neoplastic (neo) proerythroblasts is also indicated. Markers used throughout our studies for immunophenotyping of HSC, MPP, and more restricted progeny are shown. $(B)$ A model of Mi-2 $\beta$ 's specific effects on the transcriptional profiles of HSCs and early progenitors. (i) Mi-2 $\beta$ is permissive for repression of genes in the HSC compartment that fall into two categories. One consists of genes characteristic of a later stage of hemo-lymphoid differentiation (Ly, My, and Ery) that are overtly or cryptically primed for expression in the HSC compartment. The second consists of relics from an earlier stage of differentiation (ES non-hemo) that are still accessible in the HSC and that become permanently silenced upon further restriction into one of the hematopoietic fates. (ii) Mi-2 $\beta$ is also permissive for expression and priming of a significant subset of HSC-specific and HSC-myeloidspecific genes. Some of these may be key for HSC maintenance by promoting niche interactions and signaling that lead to a protracted cell cycle and guard against excessive cycling. Others may be key for myeloid lineage priming and differentiation.

cline that correlates with depletion of their downstream progeny. In vitro and in vivo differentiation studies on mutant HSC confirms their ability to progress only along the erythroid pathway and through several stages of erythroid differentiation (MEP, BFU-E, CFU-E, ProEB) before they arrest at the ProEB stage. In vivo, mutant ProEB accumulate at very high numbers, accounting for the majority of the hematopoietic compartment at later time points after $M i-2 \beta$ deletion, displaying features of erythroid leukemia (Kogan et al. 2002).

Among the genes dependent on Mi-2 $\beta$ for expression, a second major category consists of molecules that are normally shared by HSC and myeloid progenitors but not by erythroid progenitors. Expression of some of these stemmyeloid-specific genes has been implicated in the positive regulation of myeloid differentiation. In contrast, a relatively small number of stem-erythroid-specific genes is deregulated upon Mi-2 $\beta$ deletion, none of which ap- pears to be critical for erythroid lineage commitment and early differentiation. Thus Mi- $2 \beta$ is required for positive priming and expression of a key subset of the myeloid differentiation program in HSC. In the absence of Mi-2 $\beta$, activation of the myeloid program is not fully achieved, resulting in a mandatory progression into the erythroid pathway.

Of the genes that depend on Mi-2 $\beta$ for repression in the HSC compartment, some are highly expressed at later stages of hemo-lymphoid differentiation and are likely primed or poised in this primitive population. In spite of increased expression of some well-known lymphoid and myeloid factors in the mutant (i.e., Rag1, Dntt, Ccr1, and Ccr2), differentiation toward these lineages is impaired. The absence of early key regulators of myeloid differentiation combined with an unaltered force of early-primed erythroid differentiation factors in the HSC is likely to dictate progression toward the ery- 
throid pathway. Significantly, no deregulation in any of the transcriptional master regulators of either myelolymphoid or erythroid differentiation such as Sfpi1 (PU.1), Cebpa (C/EBP $\alpha)$, Cebpd (C/EBPo), Ikzf1 (Ikaros), Gata1 (GATA-1), Gata2 (GATA-2), and Klf1 (EKLF) was observed. Thus, Mi-2 $\beta$ works either independently of these early lineage-determining factors or downstream from their expression, perhaps in a fashion that is permissive to their function.

Current models of HSC homeostasis require the execution of an asymmetric division that produces, on the one hand, a long-lived HSC and, on the other hand, a progenitor cell that is capable of multilineage differentiation (Fig. 8A). Both progeny of this division apparently require the chromatin remodeler $\mathrm{Mi}-2 \beta$. Lack of $\mathrm{Mi}-2 \beta$ results in the production of short-lived HSC that can only undergo erythroid differentiation (Fig. 8A). Mi-2 $\beta$ 's role in allowing or promoting expression of several key regulators of self-renewal and myeloid differentiation in the HSC is sufficient to explain the loss of self-renewal and multilineage differentiation in this compartment (Fig. 8B). Nonetheless, Mi-2 $\beta$ 's role in gene repression in the HSC reveals another mechanism by which this remodeler can directly influence the HSC's plasticity (Fig. $8 \mathrm{~B})$. Upon loss of Mi-2 $\beta$, the derepression of primed or poised hematopoietic lineage genes may deregulate progenitor plasticity and expedite differentiation to the lineage with the most dominant lineage-promoting factors; in this case, the erythroid lineage. Importantly, Mi- $2 \beta$ directly associates with the regulatory elements of several of the derepressed genes, which also appear to be dependent on its activity for maintenance of a poised chromatin and transcriptionally inactive state. Its negative effect on histone acetylation of its target genes is consistent with a role of $\mathrm{Mi}-2 \beta$ as an integral component of the NuRD deacetylase complex. Interestingly, Mi-2 $\beta$ has also been reported in a complex with the ALL-1trithorax/Polycomb protein, deletion of which displays similar biological activities in the HSC compartment (Nakamura et al. 2002; Jude et al. 2007; McMahon et al. 2007). Thus, Mi-2 $\beta$ appears to be a key component of a wider epigenetic network that underlies the self-renewing and multilineage potential of stem cells and their immediate progeny. Future studies addressing the epigenetic and genetic networks through which Mi-2 $\beta$ operates may yield long-sought handles to manipulate lineage plasticity and maintenance of the HSC and its more mature progeny.

\section{Materials and methods}

Mice

$M i-2 \beta^{L O x P F / L O x P F}$ (designated as $M i-2 \beta^{f l / f 1}$ ) mice (Williams et al. 2004) and Mx-Cre transgenic mice (Kuhn et al. 1995) were bred and maintained under pathogen-free conditions in the animal facility at Massachusetts General Hospital, Bldg. 149-8. At the time of analysis, mice were $8-14$ wk of age. All animal experiments were done according to protocols approved by the Subcommittee on Research Animal Care at Massachusetts General
Hospital (Charlestown, MA) and in accordance with the guidelines set forth by the National Institutes of Health.

\section{Deletion of Mi-2 $\beta$}

$\mathrm{Mi}-2 \beta^{f l / f 1} ; \mathrm{Mx}-\mathrm{Cre}^{+}$mice were subjected to intraperitoneal injection with $120 \mu \mathrm{g}$ of $\mathrm{pI} \cdot \mathrm{pC}$ (Amersham Biosciences) at days 0 and 3. PI - pC was also administered to $\mathrm{Mi}-2 \beta^{f l / f 1} ; \mathrm{Mx}-\mathrm{Cre}^{-}$control littermates (designated as wild-type). Mice were analyzed at various time points, typically at days 3 (stage I), 9 (stage II), 14 (stage III), and $\geq 14$ (stage IV). Mi-2 $\beta$ deletion was confirmed by PCR analysis of genomic DNA as described previously (Williams et al. 2004) and by RT-PCR for Mi-2 $\beta$ expression for some of the analysis.

\section{Antibodies}

Antibodies and their specific clones used were CD3 (17A2), CD4 (L3T4), CD5 (53-7.3), CD8 $\alpha$ (53-6.7), CD8 $\beta$ (H35-17.2), CD19 (1D3), CD25 (PC61), CD44 (IM7), TCR $\beta$ (H57-597), TCR $\gamma \delta$ (GL3), Flt3 (A2F10.1), c-Kit (2B8), IL-7R $\alpha$ (A7R34), Sca-1 (D7 or E13-161.7), Mac-1 (M1/70), Thy1.2 (53-2.1), B220 (RA36B2), DX5, Gr-1 (RB6-8C5), CD34 (RAM34), Fc $\gamma$ RII/III (2.4G2), Ter119, NK1.1 (PK136), CD71 (C2), CD34 (RAM34), 7/4, CD45.1 (A20), and CD45.2 (104). All antibodies were purchased from BD Pharmingen, Invitrogen Caltag laboratories, and eBiosciences.

\section{HSC and progenitor purification}

BM cells were harvested from femurs and tibias and subjected to red blood cell (RBC) lysis using ACK buffer (0.15 M ammonium chloride, $10 \mathrm{mM}$ potassium bicarbonate, $0.1 \mathrm{mM}$ EDTA). Lineage-positive cells were subsequently stained with antibodies against the lineage markers TER119, B220, Mac-1, Gr-1, 7/4, CD3, CD5, CD $8 \alpha, \mathrm{CD} 8 \beta, \mathrm{CD} 19, \mathrm{TC} \beta, \mathrm{TCR} \gamma \delta$, and DX5 and removed with magnetic beads conjugated to sheep anti-rat IgG (Dynal). The remaining cells were incubated with biotin-conjugated anti-rat IgG to reveal any remaining lineage-positive cells. Cells were then stained with APC-c-Kit, PE-Cy5.5-Sca-1, PECD71 or PE-Flt3, FITC-CD34, and APC-Cy7-streptavidin prior to FACS analysis and cell sorting. For analysis of B-lineage precursors, total BM and BM-depleted cells expressing the lineage markers (Ter119, Mac-1, Gr-1, IgM, CD3, CD8a, TCR $\beta$, TCR $\gamma \delta$, DX5) were stained with the cell surface markers indicated in Figure 1. Flow cytometry was performed using a two-laser FACSCanto (BD Biosciences) or a three-laser MoFlo (Dako Cytomation). Cell sorting was performed using a three-laser MoFlo, and the files obtained were uploaded to FlowJo (Tree Star) for further analysis.

For thymocyte precursor (DN3) purification, thymocytes from $\mathrm{Mi}-2 \beta^{f 1 / f 1} ; C D 2-C r e^{+}$mice (KO) and $\mathrm{Mi}-2 \beta^{f 1 / f 1} ; h C D 2-C r e^{-}$ (wild-type) littermates were harvested and depleted for lineagepositive cells as described previously (Williams et al. 2004). $\mathrm{Lin}^{-} \mathrm{CD} 44^{-} \mathrm{CD} 25^{+}$cells were harvested as a DN3 population and used for further expression profiling studies.

\section{Methylcellulose colony forming cell (CFC) assays}

BM cells were prepared $9 \mathrm{~d}$ after Cre induction (stage II). For CFU-E assay, $5 \times 10^{4}$ nucleated cells were cultured with Methocult M3334 (Stem Cell Technologies) in 35-mm culture dishes (NUNC 174926) in duplicates. Colonies were scored after 2-3 d of culture according to the criteria described in the technical manual. For multicolony assays, $2.5 \times 10^{4}$ nucleated cells from BM were cultured with Methocult M3434 (Stem Cell Technolo- 
gies) supplemented with hTPO (50 ng/mL), hIL-11(50 ng/mL), and $\mathrm{mGM}-\mathrm{CSF}(10 \mathrm{ng} / \mathrm{mL})$ in $35-\mathrm{mm}$ culture dishes in duplicates. The colonies were scored from day 5 to day 17 according to previously described criteria (Nakahata and Ogawa 1982) and were confirmed by May-Giemsa staining (Harleco) of cytospins (400 rpm, $5 \mathrm{~min}$ ) of individual colonies. Cytokines were purchased from R\&D Systems.

\section{Cell cycle analysis}

Cell cycle profiles were analyzed as described previously (Gomez-del Arco et al. 2004). Briefly, sorted LSK, LK CD34, and LK CD71 cells were pelleted and fixed in 95\% cold ethanol overnight. The fixed cells were stained in PI staining buffer $(250$ $\mu \mathrm{g} / \mathrm{mL}$ RNase A, $50 \mu \mathrm{g} / \mathrm{mL}$ propidium iodide [PI]) for $30 \mathrm{~min}$ at $37^{\circ} \mathrm{C}$, and the DNA content was determined by the FACSCanto. Pyronin Y/Hoechest staining was performed as described previously (Cheng et al. 2000). Briefly, BM cells were depleted for lineage markers and stained with $10 \mu \mathrm{g} / \mathrm{mL}$ Hoechest 33342 (Molecular Probes) at a concentration of $10^{6}$ per milliliter in DMEM $/ 10 \%$ FCS for $45 \mathrm{~min}$ at $37^{\circ} \mathrm{C}$. After the wash in cold $\mathrm{PBS} / 2 \%$ FCS, cells were stained for c-kit-APC, Sca-1-PE-Cy7, and lineage markers in APC-Cy7 and were fixed in 5\% PFA overnight at $4^{\circ} \mathrm{C}$. The fixed cells were stained with $0.5 \mu \mathrm{g} / \mathrm{mL}$ Pyronin Y (Polysciences) at a concentration of $10^{6}$ per milliliter in $5 \%$ PFA for $30 \mathrm{~min}$ on ice prior to the analysis on LSR II (BD Biosciences).

\section{Analysis for apoptotic cells}

Annexin V/PI staining was performed according to the BD Biosciences' protocol. Briefly, lineage-depleted BM cells were stained for c-kit-APC, Sca-1-PE-Cy5.5 and the lineage markers in APC-Cy7. Cells were washed and stained with Annexin VFITC/PI in the binding buffer prior to flow cytometric analysis.

\section{In vitro HSC cultures}

BM cells from $M i-2 \beta^{f 1 / f 1}$ and $M i-2 \beta^{\Delta / \Delta}$ were prepared $3 \mathrm{~d}$ after one pI-pC injection. One-hundred to $200 \mathrm{Lin}^{-} \mathrm{Sca}-1^{+} \mathrm{c}-\mathrm{Kit}^{+}$cells were sorted onto OP9 stromal cells in 96-well plates and were cultured in IMDM $/ 20 \%$ FCS (Hyclone, certified) supplemented with mSCF (50 ng/mL), hIL-6 (20 ng/mL), mIL-3 (10 ng/mL), hErythropoietin $(3 \mathrm{U} / \mathrm{mL})$, hThrombopoietin $(50 \mathrm{ng} / \mathrm{mL})$, and hIL-11 $(50 \mathrm{ng} / \mathrm{mL})$. The differentiation to erythro-myeloid lineages at each time point was examined by antibody staining for cell surface markers followed by flow cytometry and cell sorting on MoFlo (Dako). Residual stromal cells were electronically excluded by size and granularity during FACS analysis or cell sorting. Sorted populations were subjected to RT-PCR analysis for expression of myeloid and erythroid lineage-specific genes.

\section{Generation of chimeras and analysis}

Congenic recipient mice were irradiated with a double dose of 450 rads ( $3 \mathrm{~h}$ apart) from a ${ }^{137} \mathrm{Cs}$ source (Mark1 model; J.L. Shephard and Associates). Total BM nucleated cells $\left(2 \times 10^{6}\right)$ from $\mathrm{Mi}-2 \beta^{+/ f 1}$; $\mathrm{Cre}^{-}$or $\mathrm{Mi}-2 \beta^{\Delta / f 1}$; $\mathrm{Cre}^{+}$mice or 2000 sorted LSK cells from $\mathrm{Mi}-2 \beta^{f 1 / f 1}$; $\mathrm{Cre}^{-}$or $\mathrm{Mi}-2 \beta^{f 1 / f 1}$; Cre ${ }^{+}$mice (CD45.2) were mixed with nucleated competitor BM cells $\left(1 \times 10^{5}\right.$ CD45.1) CD45.2) and injected intravenously into the irradiated recipients (CD45.2). Mice were maintained on acidified water. Chimerism in the peripheral blood was determined at 4-6 wk after the reconstitution by antibody staining with CD45.1 and CD45.2 markers prior to the induction of Mi-2 $\beta$ deletion. Mice with established chimerism were injected twice with $\mathrm{pI} \cdot \mathrm{pC}$ (with a 3-d interval) and sacrificed $9 \mathrm{~d}$ later for analysis. Contributions from donor, recipient, and competitor in peripheral blood and $\mathrm{BM} \mathrm{Lin}{ }^{-}$and $\mathrm{Lin}^{+}$compartments were measured by cell surface staining for the CD45.1 and CD45.2 markers as well as by genomic DNA analysis of the sorted populations.

\section{Microarray analysis}

HSC ( Lin $^{-} \mathrm{Scal}^{+} \mathrm{C}-\mathrm{Kit}^{+} \mathrm{CD} 71^{-}$), erythroid progenitors ( $\mathrm{Lin}^{-} \mathrm{Sca} 1^{-} \mathrm{c}-$ $\mathrm{Kit}^{+} \mathrm{CD} 34^{-} \mathrm{CD} 71^{+}$) and myeloid ( $\mathrm{Lin}^{-} \mathrm{Sca} 1^{-} \mathrm{c}-\mathrm{Kit}^{+} \mathrm{CD} 34^{+} \mathrm{CD} 71^{-}$) progenitors were isolated from wild-type and $M i-2 \beta^{\Delta / \Delta}$ BM $6 \mathrm{~d}$ after the second injection of $\mathrm{pI} \cdot \mathrm{pC}$ (stage II). Representative post-sort purity is shown in Supplemental Figure 3. Total RNA from HSC and erythroid and myeloid progenitor populations were prepared using TriZol reagent (Invitrogen) followed by purification using MEGAclear (Ambion). Biotinylated aRNA probes were synthesized by two rounds of amplification using the MessageAmp II aRNA Amplification kit (Ambion). The probes were hybridized with Affymetrix Mouse Genome 430_2.0 array chips. Affymetrix DAT files were processed using the Affymetrix-Gene Chip Operating System (GCOS) to create .CEL files. Array quality control (QC) metrics generated by Affymetrix Microarray Suite 5.0 were used to assess the quality of the hybridizations. QC consisted of visual examination of hybridization chip images, scatter plots from replicates, hierarchical clustering of arrays, RNA degradation plots, scale factor, percentage of presence call, average background, and $3^{\prime}$ to $5^{\prime}$ ratios of actin and GAPDH. For Raw intensity, .CEL files from the 18 chips, three replicates for each of the six conditions (three wild-type and three MT cell types), were then normalized by robust multichip analysis (RMA) (Bioconductor release 1.7) with PM-only models. Normalized expression values were analyzed with the Bioconductor limma package, an approach of implementation of the Empirical Bayes linear modeling (Smyth 2005). For all comparison tests, genes with an absolute fold change in transcript level exceeding 1.5 and multiple test-adjusted $P$ value $<5 \%$ were selected for further analyses. The likelihood of overrepresentation of function categories in the up- or down-regulated gene list relative to a background of all array genes was calculated by Fisher's exact test for statistical analysis.

\section{RT-PCR assays}

First-strand cDNA was synthesized using the SuperScript II First-Strand Synthesis System for RT-PCR (Invitrogen) from the total RNA prepared with the TriZol reagent (Invitrogen). The cDNA product was quantified with $A c t b$ primer pairs using SYBR Green PCR Master Mix (Applied Biosystems) on the ABI prism 7000 sequence detection system. The amount of cDNA from different populations was normalized based on Actb signals for the subsequent PCR. $\left[\alpha{ }^{32} \mathrm{P}\right] \mathrm{dCTP}$ was added into the PCR experiments in order to visualize the PCR products on a PhosphorImager screen (Molecular Dynamics) or Biomax MS film (Kodak). PCR was also performed without addition of radioactive nucleotides. The primer sequences and expected product sizes are described in Supplemental Table 4.

\section{ChIP}

ChIP and subsequent analyses were performed as described (Williams et al. 2004) with BM $\mathrm{Lin}^{-} \mathrm{Scal}^{+} \mathrm{c}-\mathrm{Kit}^{+}$(LSK), BM $\mathrm{Lin}^{-} \mathrm{Sca}^{-}{ }^{-} \mathrm{c}-\mathrm{Kit}^{+}(\mathrm{LK}), \mathrm{BM}$ and E14.5 fetal liver LSK + LK, thymocytes, and ES cells. Cells were harvested from wild-type and $\mathrm{KO}$ mice $9 \mathrm{~d}$ after induction with two $\mathrm{pI} \cdot \mathrm{pC}$ injections. For Mi-2 $\beta$ ChIP, Drosophila chromatin was used as a carrier 
(O'Neill et al. 2006). The antibodies used for ChIP are listed in Supplemental Table 6. Primer sequences are listed in Supplemental Table 5.

\section{Statistical analysis}

A two-tailed Student's $t$-test was applied to obtain $P$ values in Microsoft Excel software.

\section{Acknowledgments}

This work was supported by NIH R01AI42254-12 to K.G. We thank J. Yetz-Aldape for cell sorting, R. Czyzewski for mice husbandry, S. Kwon for technical support, and D. Dombkowski for advice for $G_{0} G_{1}$ analysis. We also thank B.A. Morgan and the Georgopoulos laboratory for critical reading of the manuscript. S.Y.N. was supported by a fellowship from the Transplantation Biology Research Center at Massachusetts General Hospital.

\section{References}

Adams, G.B., Chabner, K.T., Alley, I.R., Olson, D.P., Szczepiorkowski, Z.M., Poznansky, M.C., Kos, C.H., Pollak, M.R., Brown, E.M., and Scadden, D.T. 2006. Stem cell engraftment at the endosteal niche is specified by the calcium-sensing receptor. Nature 439: 599-603.

Adolfsson, J., Mansson, R., Buza-Vidas, N., Hultquist, A., Liuba, K., Jensen, C.T., Bryder, D., Yang, L., Borge, O.J., Thoren, L.A., et al. 2005. Identification of Flt3+ lympho-myeloid stem cells lacking erythro-megakaryocytic potential a revised road map for adult blood lineage commitment. Cell 121: 295-306.

Akashi, K., Traver, D., Miyamoto, T., and Weissman, I.L. 2000. A clonogenic common myeloid progenitor that gives rise to all myeloid lineages. Nature 404: 193-197.

Arai, F., Hirao, A., Ohmura, M., Sato, H., Matsuoka, S., Takubo, K., Ito, K., Koh, G.Y., and Suda, T. 2004. Tie2/angiopoietin-1 signaling regulates hematopoietic stem cell quiescence in the bone marrow niche. Cell 118: 149-161.

Bernstein, B.E., Mikkelsen, T.S., Xie, X., Kamal, M., Huebert, D.J., Cuff, J., Fry, B., Meissner, A., Wernig, M., Plath, K., et al. 2006. A bivalent chromatin structure marks key developmental genes in embryonic stem cells. Cell 125: 315-326.

Bowie, M.B., McKnight, K.D., Kent, D.G., McCaffrey, L., Hoodless, P.A., and Eaves, C.J. 2006. Hematopoietic stem cells proliferate until after birth and show a reversible phase-specific engraftment defect. J. Clin. Invest. 116: 2808-2816.

Bowie, M.B., Kent, D.G., Copley, M.R., and Eaves, C.J. 2007. Steel factor responsiveness regulates the high self-renewal phenotype of fetal hematopoietic stem cells. Blood 109: 5043-5048.

Buza-Vidas, N., Antonchuk, J., Qian, H., Mansson, R., Luc, S., Zandi, S., Anderson, K., Takaki, S., Nygren, J.M., Jensen, C.T., et al. 2006. Cytokines regulate postnatal hematopoietic stem cell expansion: Opposing roles of thrombopoietin and LNK. Genes \& Dev. 20: 2018-2023.

Calvi, L.M., Adams, G.B., Weibrecht, K.W., Weber, J.M., Olson, D.P., Knight, M.C., Martin, R.P., Schipani, E., Divieti, P., Bringhurst, F.R., et al. 2003. Osteoblastic cells regulate the haematopoietic stem cell niche. Nature 425: 841-846.

Cheng, T., Rodrigues, N., Shen, H., Yang, Y., Dombkowski, D., Sykes, M., and Scadden, D.T. 2000. Hematopoietic stem cell quiescence maintained by p21cip1/waf1. Science 287: 18041808.

Cheshier, S.H., Morrison, S.J., Liao, X., and Weissman, I.L. 1999.
In vivo proliferation and cell cycle kinetics of long-term selfrenewing hematopoietic stem cells. Proc. Natl. Acad. Sci. 96: $3120-3125$.

Christensen, J.L. and Weissman, I.L. 2001. Flk-2 is a marker in hematopoietic stem cell differentiation: A simple method to isolate long-term stem cells. Proc. Nat1. Acad. Sci. 98: 14541-14546.

Colgan, J. and Rothman, P. 2006. All in the family: IL-27 suppression of T(H)-17 cells. Nat. Immunol. 7: 899-901.

de Haan, G. and Van Zant, G. 1997. Intrinsic and extrinsic control of hemopoietic stem cell numbers: Mapping of a stem cell gene. J. Exp. Med. 186: 529-536.

Fortunel, N.O., Hatzfeld, A., and Hatzfeld, J.A. 2000. Transforming growth factor- $\beta$ : Pleiotropic role in the regulation of hematopoiesis. Blood 96: 2022-2036.

Georgopoulos, K. 2002. Haematopoietic cell-fate decisions, chromatin regulation and ikaros. Nat. Rev. Immunol. 2: 162-174.

Gomez-del Arco, P., Maki, K., and Georgopoulos, K. 2004. Phosphorylation controls Ikaros's ability to negatively regulate the G(1)-S transition. Mol. Cell. Biol. 24: 2797-2807.

Hu, M., Krause, D., Greaves, M., Sharkis, S., Dexter, M., Heyworth, C., and Enver, T. 1997. Multilineage gene expression precedes commitment in the hemopoietic system. Genes \& Dev. 11: 774-785.

Ivanova, N.B., Dimos, J.T., Schaniel, C., Hackney, J.A., Moore, K.A., and Lemischka, I.R. 2002. A stem cell molecular signature. Science 298: 601-604.

Janzen, V., Forkert, R., Fleming, H.E., Saito, Y., Waring, M.T., Dombkowski, D.M., Cheng, T., DePinho, R.A., Sharpless, N.E., and Scadden, D.T. 2006. Stem-cell ageing modified by the cyclin-dependent kinase inhibitor p16INK4a. Nature 443: 421-426.

Jimenez, G., Griffiths, S.D., Ford, A.M., Greaves, M.F., and Enver, T. 1992. Activation of the $\beta$-globin locus control region precedes commitment to the erythroid lineage. Proc. Natl. Acad. Sci. 89: 10618-10622.

Jude, C.D., Climer, L., Xu, D., Artinger, E., Fisher, J.K., and Ernst, P. 2007. Unique and independent roles for MLL in adult hematopoietic stem cells and progenitors. Cell Stem Cell 1: 324-337.

Kaji, K., Caballero, I.M., MacLeod, R., Nichols, J., Wilson, V.A., and Hendrich, B. 2006. The NuRD component Mbd3 is required for pluripotency of embryonic stem cells. Nat. Cell Biol. 8: 285-292.

Kim, J., Sif, S., Jones, B., Jackson, A., Koipally, J., Heller, E., Winandy, S., Viel, A., Sawyer, A., Ikeda, T., et al. 1999. Ikaros DNA-binding proteins direct formation of chromatin remodeling complexes in lymphocytes. Immunity 10: 345 355.

Kirstetter, P., Anderson, K., Porse, B.T., Jacobsen, S.E., and Nerlov, C. 2006. Activation of the canonical Wnt pathway leads to loss of hematopoietic stem cell repopulation and multilineage differentiation block. Nat. Immunol. 7: 1048-1056.

Kogan, S.C., Ward, J.M., Anver, M.R., Berman, J.J., Brayton, C., Cardiff, R.D., Carter, J.S., de Coronado, S., Downing, J.R., Fredrickson, T.N., et al. 2002. Bethesda proposals for classification of nonlymphoid hematopoietic neoplasms in mice. Blood 100: 238-245.

Kontaraki, J., Chen, H.H., Riggs, A., and Bonifer, C. 2000. Chromatin fine structure profiles for a developmentally regulated gene: Reorganization of the lysozyme locus before trans-activator binding and gene expression. Genes \& Dev. 14: 2106 2122.

Kuhn, R., Schwenk, F., Aguet, M., and Rajewsky, K. 1995. Inducible gene targeting in mice. Science 269: 1427-1429. 
Lai, A.Y. and Kondo, M. 2006. Asymmetrical lymphoid and myeloid lineage commitment in multipotent hematopoietic progenitors. J. Exp. Med. 203: 1867-1873.

Lemischka, I.R. and Moore, K.A. 2003. Stem cells: Interactive niches. Nature 425: 778-779.

Liang, Y., Jansen, M., Aronow, B., Geiger, H., and Van Zant, G. 2007. The quantitative trait gene latexin influences the size of the hematopoietic stem cell population in mice. Nat. Genet. 39: 178-188.

Linder, B., Mentele, E., Mansperger, K., Straub, T., Kremmer, E., and Rupp, R.A. 2007. CHD4/Mi-2 $\beta$ activity is required for the positioning of the mesoderm/neuroectoderm boundary in Xenopus. Genes \& Dev. 21: 973-983.

Mansson, R., Hultquist, A., Luc, S., Yang, L., Anderson, K., Kharazi, S., Al-Hashmi, S., Liuba, K., Thoren, L., Adolfsson, J., et al. 2007. Molecular evidence for hierarchical transcriptional lineage priming in fetal and adult stem cells and multipotent progenitors. Immunity 26: 407-419.

McMahon, K.A., Hiew, S.Y.L., Hadjur, S., Veiga-Fernandes, H., Menzel, U., Price, A.J., Kioussis, D., Williams, O., and Brady, H.J.M. 2007. MII has a critical role in fetal and adult hematopoietic stem cell self-renewal. Cell Stem Cell 1: 338-345.

Miyamoto, T. and Akashi, K. 2005. Lineage promiscuous expression of transcription factors in normal hematopoiesis. Int. J. Hematol. 81: 361-367.

Miyamoto, T., Iwasaki, H., Reizis, B., Ye, M., Graf, T., Weissman, I.L., and Akashi, K. 2002. Myeloid or lymphoid promiscuity as a critical step in hematopoietic lineage commitment. Dev. Cell 3: 137-147.

Moore, K.A. and Lemischka, I.R. 2006. Stem cells and their niches. Science 311: 1880-1885.

Morrison, S.J. and Weissman, I.L. 1994. The long-term repopulating subset of hematopoietic stem cells is deterministic and isolatable by phenotype. Immunity 1: 661-673.

Naito, T., Gomez-Del Arco, P., Williams, C.J., and Georgopoulos, K. 2007. Antagonistic interactions between Ikaros and the chromatin remodeler Mi- $2 \beta$ determine silencer activity and $\mathrm{Cd} 4$ gene expression. Immunity 27: 723-734.

Nakahata, T. and Ogawa, M. 1982. Clonal origin of murine hemopoietic colonies with apparent restriction to granuclocyte-macrophage-megakaryocyte (GMM) differentiation. I. Cell. Physiol. 111: 239-246.

Nakamura, T., Mori, T., Tada, S., Krajewski, W., Rozovskaia, T., Wassell, R., Dubois, G., Mazo, A., Croce, C.M., and Canaani, E. 2002. ALL-1 is a histone methyltransferase that assembles a supercomplex of proteins involved in transcriptional regulation. Mol. Cell 10: 1119-1128.

$\mathrm{Ng}$, S.Y., Yoshida, T., and Georgopoulos, K. 2007. Ikaros and chromatin regulation in early hematopoiesis. Curr. Opin. Immunol. 19: 116-122.

Oguro, H., Iwama, A., Morita, Y., Kamijo, T., van Lohuizen, M., and Nakauchi, H. 2006. Differential impact of Ink4a and Arf on hematopoietic stem cells and their bone marrow microenvironment in Bmil-deficient mice. J. Exp. Med. 203: 22472253.

O'Neill, D.W., Schoetz, S.S., Lopez, R.A., Castle, M., Rabinowitz, L., Shor, E., Krawchuk, D., Goll, M.G., Renz, M., Seelig, H.P., et al. 2000. An ikaros-containing chromatin-remodeling complex in adult-type erythroid cells. Mol. Cell. Biol. 20: 7572-7582.

O'Neill, L.P., VerMilyea, M.D., and Turner, B.M. 2006. Epigenetic characterization of the early embryo with a chromatin immunoprecipitation protocol applicable to small cell populations. Nat. Genet. 38: 835-841.

Park, I.K., Qian, D., Kiel, M., Becker, M.W., Pihalja, M., Weissman, I.L., Morrison, S.J., and Clarke, M.F. 2003. Bmi-1 is required for maintenance of adult self-renewing haematopoietic stem cells. Nature 423: 302-305.

Pupa, S.M., Menard, S., Forti, S., and Tagliabue, E. 2002. New insights into the role of extracellular matrix during tumor onset and progression. J. Cell. Physiol. 192: 259-267.

Qian, M., Buza-Vidas, N., Hyland, C.D., Jensen, C.T., Antonchuk, J., Månsson, R., Thoren, L.A., Ekblom, M., Alexander, W.S., and Jacobsen, S.E.W. 2007. Critical role of thrombopoietin in maintaining adult quiescent hematopoietic stem cells. Cell Stem Cell 1: 671-684.

Ramalho-Santos, M., Yoon, S., Matsuzaki, Y., Mulligan, R.C., and Melton, D.A. 2002. 'Stemness': Transcriptional profiling of embryonic and adult stem cells. Science 298: 597-600.

Reya, T., Duncan, A.W., Ailles, L., Domen, J., Scherer, D.C., Willert, K., Hintz, L., Nusse, R., and Weissman, I.L. 2003. A role for Wnt signalling in self-renewal of haematopoietic stem cells. Nature 423: 409-414.

Rodriguez, P., Bonte, E., Krijgsveld, J., Kolodziej, K.E., Guyot, B., Heck, A.J., Vyas, P., de Boer, E., Grosveld, F., and Strouboulis, J. 2005. GATA-1 forms distinct activating and repressive complexes in erythroid cells. EMBO J. 24: 23542366.

Scheller, M., Huelsken, J., Rosenbauer, F., Taketo, M.M., Birchmeier, W., Tenen, D.G., and Leutz, A. 2006. Hematopoietic stem cell and multilineage defects generated by constitutive $\beta$-catenin activation. Nat. Immunol. 7: 1037-1047.

Sharma, S., Gurudutta, G.U., Satija, N.K., Pati, S., Afrin, F., Gupta, P., Verma, Y.K., Singh, V.K., and Tripathi, R.P. 2006. Stem cell c-KIT and HOXB4 genes: Critical roles and mechanisms in self-renewal, proliferation, and differentiation. Stem Cells Dev. 15: 755-778.

Shimizu, M., Shimamura, M., Owaki, T., Asakawa, M., Fujita, K., Kudo, M., Iwakura, Y., Takeda, Y., Luster, A.D., Mizuguchi, J., et al. 2006. Antiangiogenic and antitumor activities of IL-27. J. Immunol. 176: 7317-7324.

Shimono, Y., Murakami, H., Kawai, K., Wade, P.A., Shimokata, K., and Takahashi, M. 2003. Mi-2 $\beta$ associates with BRG1 and RET finger protein at the distinct regions with transcriptional activating and repressing abilities. J. Biol. Chem. 278: 51638-51645.

Smyth, G.K. 2005. Limma: Linear models for microarray data, In Bioinformatics and computational biology solutions using $R$ and bioconductor $R$ (eds. V. Gentleman et al.), pp. 397-420. Springer, New York.

Socolovsky, M., Nam, H., Fleming, M.D., Haase, V.H., Brugnara, C., and Lodish, H.F. 2001. Ineffective erythropoiesis in Stat $5 \mathrm{a}^{-/-} 5 \mathrm{~b}^{-/-}$mice due to decreased survival of early erythroblasts. Blood 98: 3261-3273.

Sridharan, R. and Smale, S.T. 2007. Predominant interaction of both Ikaros and Helios with the NuRD complex in immature thymocytes. J. Biol. Chem. 282: 30227-30238.

Suzuki, N., Suwabe, N., Ohneda, O., Obara, N., Imagawa, S., Pan, X., Motohashi, H., and Yamamoto, M. 2003. Identification and characterization of 2 types of erythroid progenitors that express GATA-1 at distinct levels. Blood 102: 35753583.

Terszowski, G., Waskow, C., Conradt, P., Lenze, D., Koenigsmann, J., Carstanjen, D., Horak, I., and Rodewald, H.R. 2005 Prospective isolation and global gene expression analysis of the erythrocyte colony-forming unit (CFU-E). Blood 105: 1937-1945.

Tong, J.K., Hassig, C.A., Schnitzler, G.R., Kingston, R.E., and Schreiber, S.L. 1998. Chromatin deacetylation by an ATPdependent nucleosome remodelling complex. Nature 395: 917-921.

Trowbridge, J.J., Scott, M.P., and Bhatia, M. 2006. Hedgehog 
modulates cell cycle regulators in stem cells to control hematopoietic regeneration. Proc. Natl. Acad. Sci. 103: 1413414139.

Wade, P.A., Gegonne, A., Jones, P.L., Ballestar, E., Aubry, F., and Wolffe, A.P. 1999. Mi-2 complex couples DNA methylation to chromatin remodelling and histone deacetylation. Nat. Genet. 23: 62-66.

Weissman, I.L. 2000. Stem cells: Units of development, units of regeneration, and units in evolution. Cell 100: 157-168.

Williams, C.J., Naito, T., Arco, P.G., Seavitt, J.R., Cashman, S.M., De Souza, B., Qi, X., Keables, P., Von Andrian, U.H., and Georgopoulos, K. 2004. The chromatin remodeler Mi-2 $\beta$ is required for CD4 expression and T cell development. Immunity 20: 719-733.

Xue, Y., Wong, J., Moreno, G.T., Young, M.K., Cote, J., and Wang, W. 1998. NURD, a novel complex with both ATPdependent chromatin-remodeling and histone deacetylase activities. Mol. Cell 2: 851-861.

Yamazaki, S., Iwama, A., Takayanagi, S., Morita, Y., Eto, K., Ema, H., and Nakauchi, H. 2006. Cytokine signals modulated via lipid rafts mimic niche signals and induce hibernation in hematopoietic stem cells. EMBO J. 25: 3515-3523.

Yang, L., Bryder, D., Adolfsson, J., Nygren, J., Mansson, R., Sigvardsson, M., and Jacobsen, S.E. 2005. Identification of $\mathrm{Lin}^{-} \mathrm{Sca} 1^{+} \mathrm{kit}^{+} \mathrm{CD} 34^{+} \mathrm{Flt}^{-}$short-term hematopoietic stem cells capable of rapidly reconstituting and rescuing myeloablated transplant recipients. Blood 105: 2717-2723.

Yilmaz, O.H., Valdez, R., Theisen, B.K., Guo, W., Ferguson, D.O., Wu, H., and Morrison, S.J. 2006. Pten dependence distinguishes haematopoietic stem cells from leukaemia-initiating cells. Nature 441: 475-482.

Yoshida, T., Ng, S.Y., Zuniga-Pflucker, J.C., and Georgopoulos, K. 2006. Early hematopoietic lineage restrictions directed by Ikaros. Nat. Immunol. 7: 382-391.

Yoshihara, H., Arai, F., Hosokawa, K., Hagiwara, T., Takubo, K., Nakamura, Y., Gomei, Y., Iwasaki, H., Matsuoka, S., Miyamoto, M., et al. 2007. Thrombopoietin/MPL signaling regulates hematopoietic stem cell quiescence and interaction with the osteoblastic niche. Cell Stem Cell 1: 685-697.

Yu, H., Yuan, Y., Shen, H., and Cheng, T. 2006. Hematopoietic stem cell exhaustion impacted by p18 INK4C and p21 Cip1/ Waf1 in opposite manners. Blood 107: 1200-1206.

Yuan, Y., Shen, H., Franklin, D.S., Scadden, D.T., and Cheng, T. 2004. In vivo self-renewing divisions of haematopoietic stem cells are increased in the absence of the early G1-phase inhibitor, p18INK4C. Nat. Cell Biol. 6: 436-442.

Zhang, Y., LeRoy, G., Seelig, H.P., Lane, W.S., and Reinberg, D. 1998. The dermatomyositis-specific autoantigen Mi2 is a component of a complex containing histone deacetylase and nucleosome remodeling activities. Cell 95: 279-289.

Zhang, J., Niu, C., Ye, L., Huang, H., He, X., Tong, W.G., Ross, J., Haug, J., Johnson, T., Feng, J.Q., et al. 2003. Identification of the haematopoietic stem cell niche and control of the niche size. Nature 425: 836-841.

Zhang, J., Grindley, J.C., Yin, T., Jayasinghe, S., He, X.C., Ross, J.T., Haug, J.S., Rupp, D., Porter-Westpfahl, K.S., Wiedemann, L.M., et al. 2006. PTEN maintains haematopoietic stem cells and acts in lineage choice and leukaemia prevention. Nature 441: 518-522. 


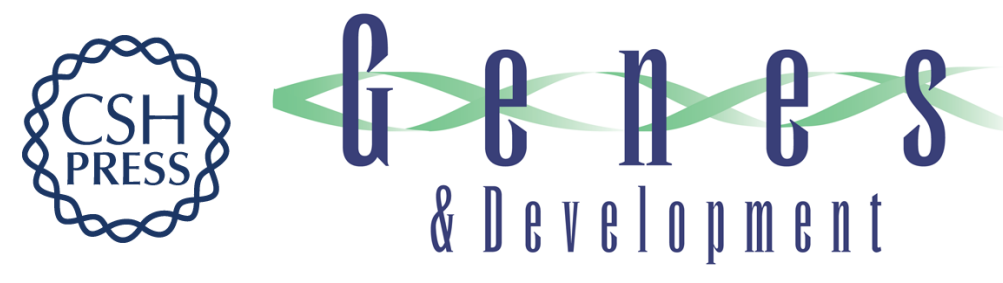

\section{The role of the chromatin remodeler Mi-2 $\beta$ in hematopoietic stem cell self-renewal and multilineage differentiation}

Toshimi Yoshida, Idit Hazan, Jiangwen Zhang, et al.

Genes Dev. 2008, 22:

Access the most recent version at doi:10.1101/gad.1642808

Supplemental http://genesdev.cshlp.org/content/suppl/2008/04/14/22.9.1174.DC1
Material

References This article cites 75 articles, 30 of which can be accessed free at:

http://genesdev.cshlp.org/content/22/9/1174.full.html\#ref-list-1

License

Email Alerting Receive free email alerts when new articles cite this article - sign up in the box at the top

Service right corner of the article or click here.

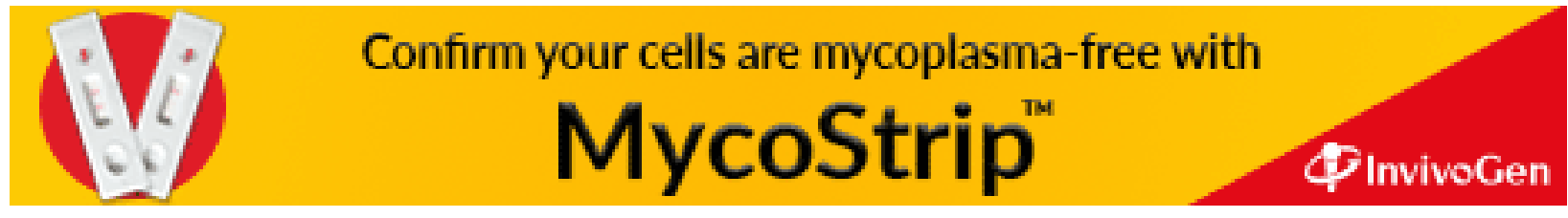

